\title{
PROCAINE NERVE BLOCK IN THE INVESTIGATION OF PERIPHERAL NERVE INJURIES *
}

\author{
BY
}

\section{W. BREMNER HIGHET}

From the Nuffield Department of Orthopadic Surgery, Oxford

(Received 1st August, 1942)

DURING the past two years at the Oxford Peripheral Nerve Injury Centre I have found that a great deal of information may be gained by the simple procedure of anæsthetizing peripheral nerves with procaine. The procedure is not original-it has been employed by $J$. C. White in the investigation of peripheral vascular disorders, and by Woollard in the investigation of sensory dissociation. I have employed nerve blocks in over fifty cases and have succeeded in establishing a satisfactory technique. In no case has there been evidence that the procedure is harmful.

Nerve block has been used in the following investigations:

1. Anomalous innervation of muscles.

2. "Supplementary" and Trick movements.

3. Sensory and sudomotor distribution of peripheral nerves, in relation to the differentiation of complete and incomplete or recovering lesions.

4. The vasomotor distribution of peripheral nerves.

Technique.-I have tried out several methods of injection and have now found a reliable method by means of which any nerve can be readily anæsthetized for a period of from three to four hours - a time sufficient for the completion of all necessary investigations. Originally I employed various strengths of procaine without adrenalin, but soon found that the block induced was of insufficient duration. Five per cent. procaine was especially unsatisfactory because several patients complained of considerable pain when the effects of injection wore off. I now employ a 2 per cent. solution of procaine containing adrenalin at a strength of 1 in 50,000 .

If possible the nerve to be blocked is identified by palpation. This is possible in the case of the ulnar above the medial epicondyle and in the radial at the level of mid-arm and the lateral popliteal at the neck of the fibula. In the case of small cutaneous nerves such as the medial or lateral cutaneous nerves of the forearm, the superficial radial or the sural nerve the course of the nerve may be mapped out by percutaneous unipolar faradic stimulation. In the case of deeply placed impalpable nerves such as the median or medial popliteal the surface marking is outlined and an attempt is made to locate the nerve with the exploring needle passed through the skin.

In all cases I employ the apparatus shown in Fig. 1. This apparatus is designed for direct unipolar stimulation of the nerve to be injected. The outside of the needle is coated with a phenyl resin which insulates all but 1 or $2 \mathrm{~mm}$. at the tip. The needle is attached to a record syringe containing 2 per cent. procaine with $1 / 50,000$ adrenalin. To the metallic part of the lower end of the barrel is attached a small metal clip and a length of insulated wire nine inches in length. This clip and its attached wire are sterile. To the end of this wire is clipped an unsterile cable leading to one terminal of an ordinary faradic coil. The other terminal leads off to a broad moist plate applied to some neutral area such as the back of the thigh. Thus when the apparatus is connected only the tip of the exploring needle acts as a stimulator, and as soon as the nerve is touched the patient experiences a tingling over the peripheral distribution of the nerve. It may be noted that in normal nerves only a very weak stimulus is tolerated. Excessive stimulation causes severe pain. Only the finest hypo-

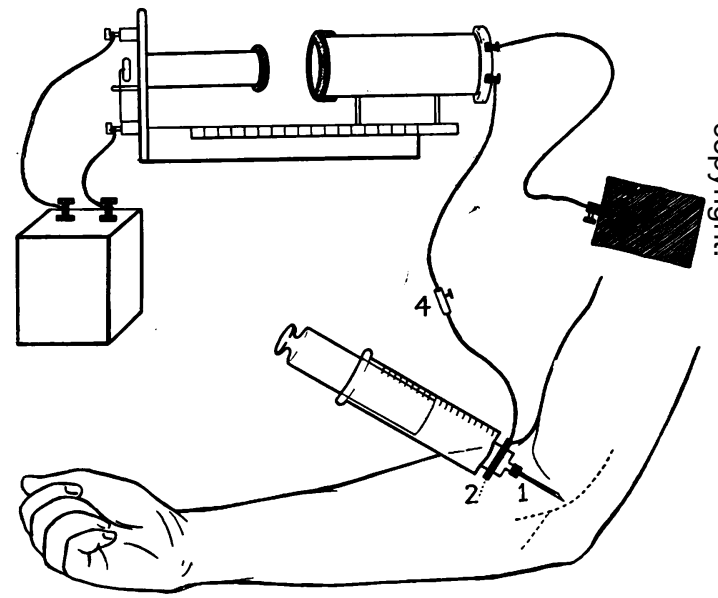

FIG. 1.-1. Hypodermic needle coated with insulating phenyl resin except at the extreme tip. 2. Clip attached to the metallic base of the syringe. The needle, syringe, clip and the attached lead are sterile. 3. Neutral plate usually applied to the thigh. 4. Connection between sterile and unsterile lead.

dermic needles are employed. I have seen no ill effects from the injection, but it is conceivable that if a large needle were used some intraneural vessels might be damaged and the intraneural hæmorrhage lead to permanent damage.

In the case of the ulnar, radial and lateral popliteal nerves an intraneural injection may be made and only 2 c.c. of solution is necessary for complete anæsthetization. In other nerves intraneural injection is rarely possible. The solution is injected around the nerve and 5 to 10 c.c. may be necessary for complete anæsthetization. If carried out slowly and carefully the injection rarely gives rise to more than a momentary slight pain. After the injection the needle is left in place. If the block is successful one finds that within a few minutes the faradic stimulus may be greatly increased without 
causing pain. It is essential to use as small a quantity of solution as possible and to block the nerve at a site remote from other main nerve trunks. If large quantities are injected the solution may diffuse and block nerves some distance from the site of injection. For instance, if the technique of injection is faulty it is possible to block the medial cutaneous nerve of the arm in the course of ulnar block at the elbow, and in the course of median block at the wrist the ulnar nerve may be affected. Indeed median nerve block at the wrist is extremely difficult on account of this possibility of spread to the ulnar.

\section{Criteria of Completeness of Nerve Block}

The order of loss of function after procaine block is well established (Gasser and Erlanger, 1929) and I have nothing to add to what is already known. The effects are peripheral vasodilatation, loss of

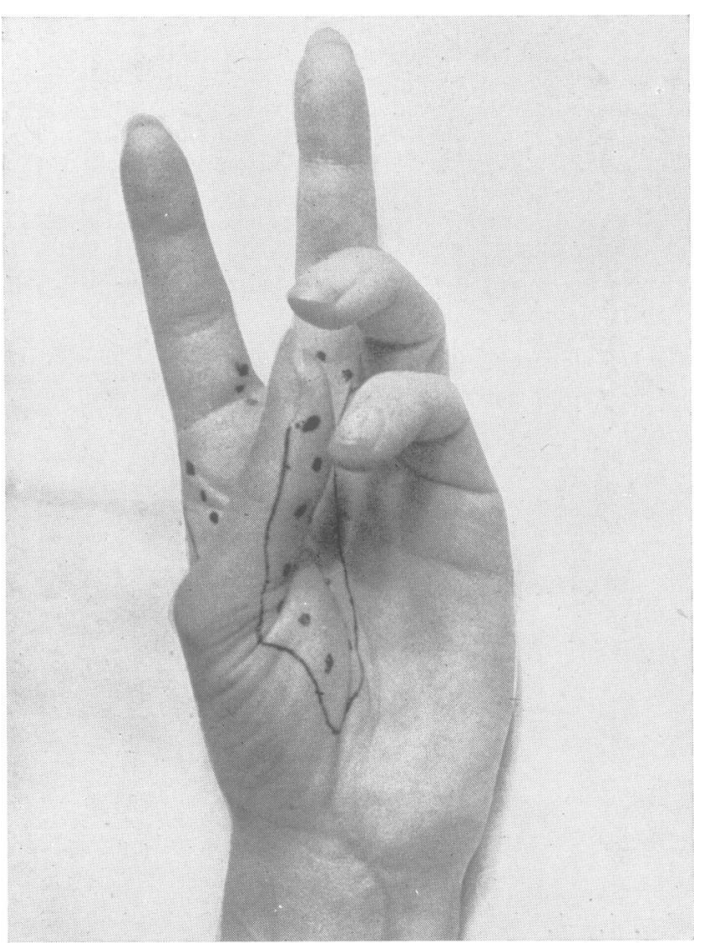

FIG. 2.

sweating, hypoalgesia, and lastly complete analgesia and anæsthesia and motor paralysis. If the injection is sub-epineural the effects appear within a minute or two, but if the solution is merely diffused about the nerve, the effects appear gradually and complete anæsthetization may take 10 to 15 minutes. When adrenalin is employed the effects persist from 3 to 4 hours.

Before a nerve block is regarded as complete, all of the following conditions must be fulfilled:

1. Full vasodilatation

$\left.\begin{array}{l}\text { 2. Anhidrosis } \\ \text { 3. Anæsthesia and analgesia }\end{array}\right\} \begin{aligned} & \text { ous zone } \\ & \text { nerve. }\end{aligned}$

4. Complete and lasting paralysis of muscles supplied by the nerve distal to the site of block.
Investigation of anomalous innervation of muscles

In a previous paper (Guttman and Highet 1942), I have discussed the innervation of the muscles of the thenar eminence. In many cases of injury to the median nerve one or another of the thenar muscles which, according to the classical description, are innervated by the median, may remain unparalysed, and so give rise to uncertainty in diagnosis. Is the median lesion incomplete or has the muscle an anomalous ulnar innervation? Fig. 2 shows attempted opposition in a case where flexor brevis pollicis and probably part of opponens pollicis were active. The correct diagnosis was readily established by means of procaine block of the ulnar nerve at the elbow. All activity in the thenar muscles was abolished.

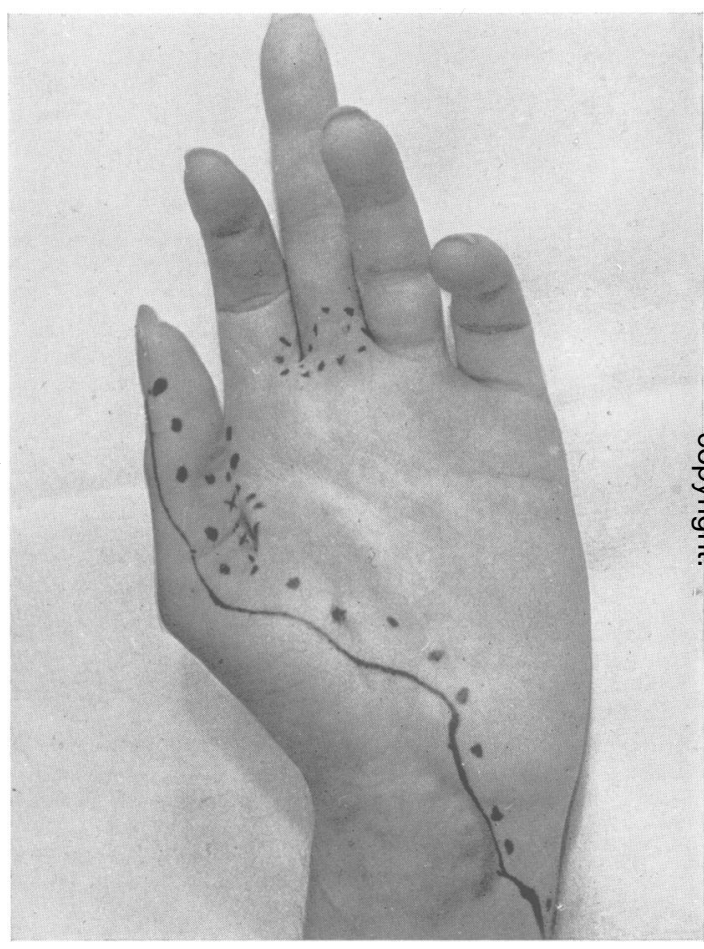

FIG. 3.

Fig. 3 shows attempted opposition after ulnar nerve block. Later at operative exploration the median nerve was found completely divided.

The innervation of flexor profundus digitorum is subject to considerable variation. Usually the slips of the muscle to the 2 nd and 3 rd digits are innervated by the median and the slips to the 4th and 5th by the ulnar. The slips to the $3 \mathrm{rd}$ and 4 th digits frequently receive a double innervation. In some cases the slip to the 5th digit may also receive a median innervation. We have not yet seen a case in which the slip to index was innervated by the ulnar nerve.

In Fig 20 flexion of the fingers is shown in a case of injury to the ulnar nerve above the level of the elbow. There was complete motor paralysis (including flexor carpi ulnaris) with the exception that 
flexor profundus digitorum to the 4 th digit was normal and that to the 5th digit only slightly weaker than normal. In addition, as will be mentioned later, the area of sensory loss was unusually small. In this case the median innervation of flexor profundus to the 4th and 5th digits was established by nerve block. First the ulnar nerve was blocked immediately above the level of the lesion. The block was almost certainly complete because the unipolar stimulating needle was employed and after the injection no pain could be aroused by faradic stimulation. The function of the long flexors remained unaltered. However, there is a real difficulty in this connection. After block of an injured nerve what means has one of assessing the completeness of the block? Failure to arouse pain by direct stimulation is an insufficient criterion because although the pain fibres are anæsthetized the motor fibres may still be unaffected. Nevertheless in this case strong stimulation by means of the exploring needle failed to bring about any contraction in flexor profundus.

Secondly, a few days later the median nerve was blocked in the antecubital fossa. The block was complete according to the four criteria mentioned above. This block was conclusive for flexor profundus digitorum was completely paralysed (Fig. 23). Subsequent operative exploration confirmed the completeness of the injury to the ulnar nerve.

\section{Investigation of " Supplementary" and " Trick" Movements}

Excluding anomalous and double innervation of muscles as a source of "trick" movements there are two classes of so-called " trick" movements which deserve separate description. "Supplementary" movements at a joint are performed by the contraction of muscles which are able to take over the function of the paralysed muscles. Most of these supplementary actions are well known. For instance, abductor pollicis longus can flex the wrist in cases of complete ulnar and median paralysis. The common flexor group of muscles, chiefly pronator teres and flexor carpi radialis, can sometimes flex the elbow when biceps, brachialis and brachio-radialis are paralysed. It is inaccurate to include such supplementary movements under the general term "trick" movements. Supplementary movements are to be encouraged as much as possible, and the patient should never be told they are tricks. The term " trick movement " should be reserved for movement where the examiner may be " tricked" by his faulty method of examination. True trick movements are all passive movements and are brought about by three agencies (WoodJones, 1921). 1. Tension on paralysed muscles by the overaction of their antagonists. 2. "Rebound" movements. 3. The action of gravity. I am not concerned here with true trick movements but with supplementary movements. By means of peripheral nerve block it is possible to identify the muscle or muscles which are responsible for the supplementary movement. In most cases of course the identity of the muscle is obvious, but in certain cases nerve block is of value.

I have encountered several cases of complete paralysis of the deltoid muscle where full active abduction of the shoulder was possible. The four main muscles responsible for abduction at the shoulder are the deltoid, supraspinatus, trapezius, and serratus anterior. Paralysis of any one muscle affects abduction. When deltoid and supraspinatus are both paralysed there is no active abduction at the scapulo-humeral joint. When deltoid alone is paralysed full abduction may be possible. One would assume that this is due to the supplementary action of supraspinatus, but it has been suggested that the long head of biceps is capable of carrying out supplementary abduction. That the supplementary abduction is due to supraspinatus may be readily demonstrated by nerve block of the suprascapular nerve at the level of the suprascapular notch of the scapula. This nerve block is rather difficult, but I have been successful on five occasions and have produced complete paralysis of supraspinatus and infraspinatus. Fig. 4 illustrates full active abduction of the shoulder in a case of complete paralysis of the deltoid. Fig. 5 shows that abduction at the scapulohumeral joint has been abolished by paralysis of supraspinatus after blocking the suprascapular nerve.

In several cases of complete radial paralysis I have observed active extension of the terminal phalanx of the thumb. This was a true supplementary movement for the thumb was held in such a position that " trick" extension by passive tension on extensor longus pollicis was prevented. Sometimes a slip of abductor brevis pollicis gains insertion into the radial side of the tendon of extensor longus pollicis. I was able to demonstrate by median nerve block that when the abductor brevis pollicis was paralysed active extension of the terminal phalanx was no longer possible.

\section{Investigation of Sensory and Sudomotor Distribution of Peripheral Nerves}

The area of skin supplied exclusively by one nerve is referred to as the autonomous zone of sensory distribution. In this zone all modalities of cutaneous sensibility are lost after nerve section. However, this autonomous zone does not represent the total area of distribution, for if all neighbouring nerves are divided and the nerve in question left intact the area of distribution will be found to be much more extensive than the autonomous zone, and this residual area is referred to as the maximal zone. The difference in size between the autonomous and maximal zones is due to nerve overlap. From macroscopic dissection it is impossible to attain an adequate insight into the distribution of cutaneous nerves. The autonomous zone of a sensory nerve is invariably of less extent than its anatomical distribution. Furthermore, there are considerable variations in the distribution of sensory nerves, both in different individuals and in the same individual on right and left sides. The difference in the size of the autonomous and maxima 
zones of any given nerve in any given patient may readily be demonstrated by means of peripheral nerve block. Another source of difficulty is that after nerve section the area of sensory loss tends to undergo progressive shrinkage especially in the first few weeks after section. This shrinkage is due to nerve overlap and concerns chiefly the nerve fibres

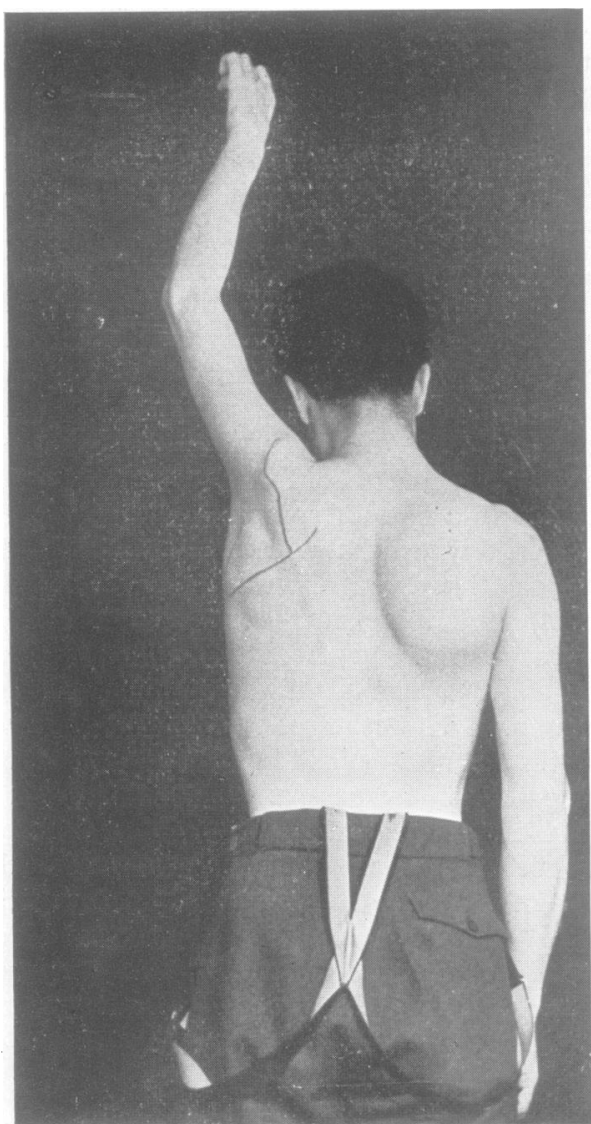

FIG. 4.

subserving touch (Pollock, 1920; Weddell, Guttmann and Gutmann, 1941).

The clinical problems may be stated as follows:

1. When a nerve is injured and the area of sensory loss is anomalous one may be uncertain whether the lesion is complete or partial.

2. When the area of sensory loss undergoes shrinkage one may be uncertain whether this shrinkage is due merely to overlap or to regeneration in the injured nerve. block.

There are two methods available. First, the affected nerve may be blocked immediately above or below the site of injury. This method is open to the serious objection that there are no adequate criteria of the completeness of the block. Secondly, the neighbouring nerves may be blocked. This is the better method, since one can be certain of the completeness of the block.

\section{Illustrative Cases}

The following cases illustrate the usefulness of nerve block. In the photographs the area of sweating is black and areas of hypohidrosis show fine

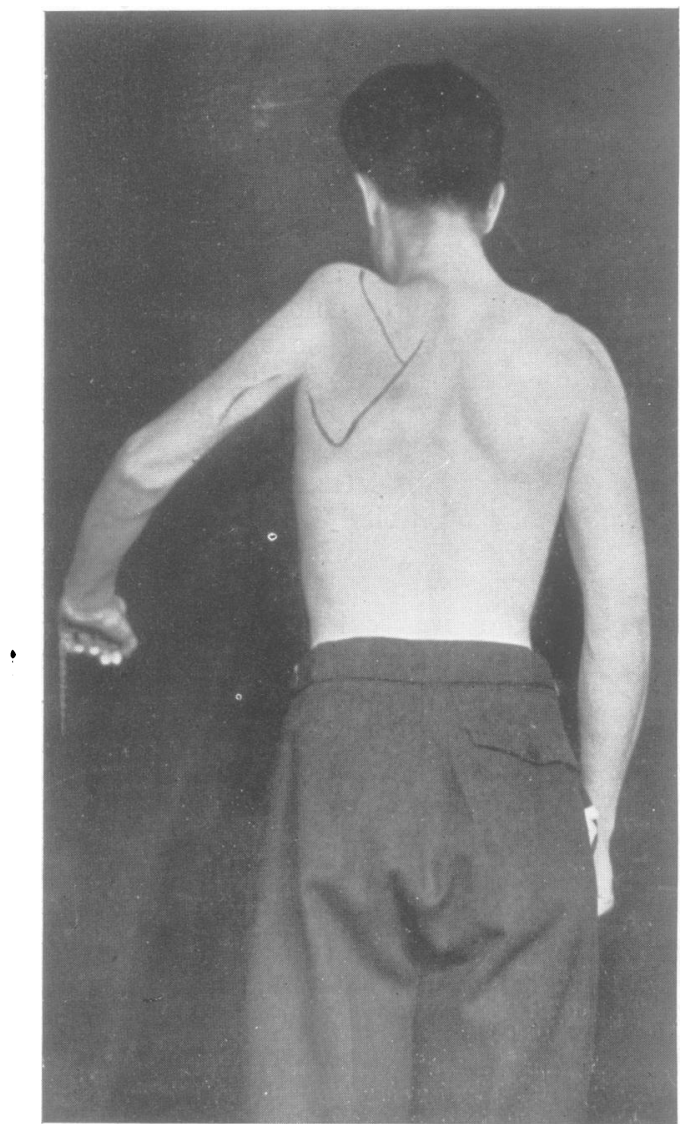

FIG. 5.

black pin-points of sweating. The border of anæsthesia to a 1 gram. von Frey hair is represented by a continuous line, the border of anæsthesia to cotton wool by a notched line. The border of analgesia to superficial needle prick is represented by black dots, so that pain sensibility is present wherever dots are marked within the touch line. The crosses represent the presence of pain sensibility to slightly deeper needle pricks (deep cutaneous pain) (Guttmann and Highet, 1942).

Case 1.-Figs. 6 to 16 illustrate a series of nerve blocks in a patient in whom complete division of the median nerve was established by nerve blocks and later confirmed by operative exploration. The nerve blocks were performed when the case was referred to us five months after the nerve injury and operative exploration was performed within a few weeks of the investigation.

The diagnosis in this case was very difficult because all thenar muscles were innervated by the ulnar nerve (Fig. 6). Figs. 7 and 8 show the autonomous zone of 


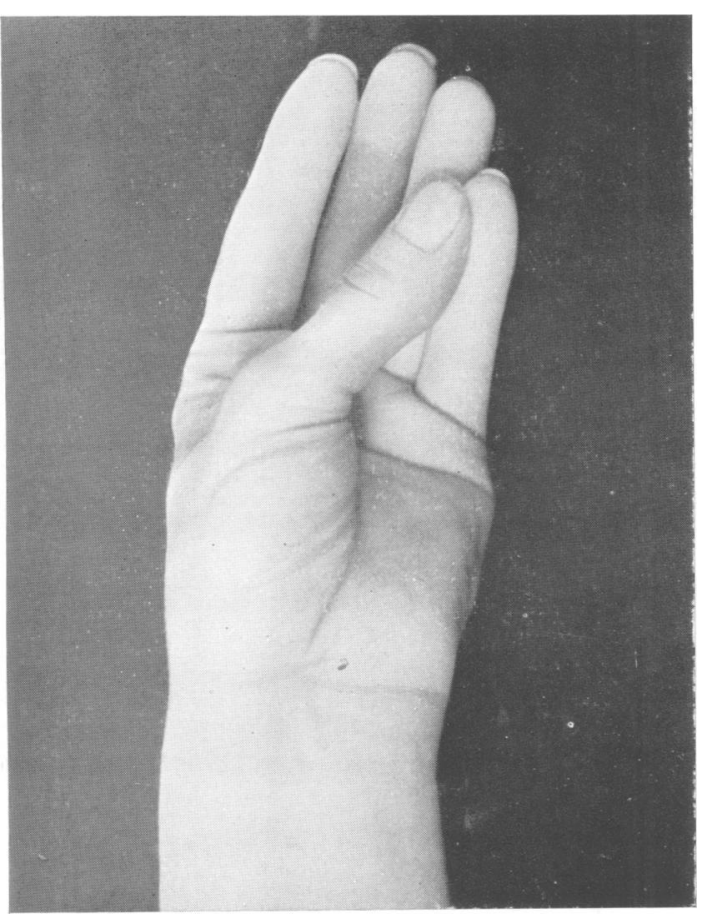

FIG. 6.

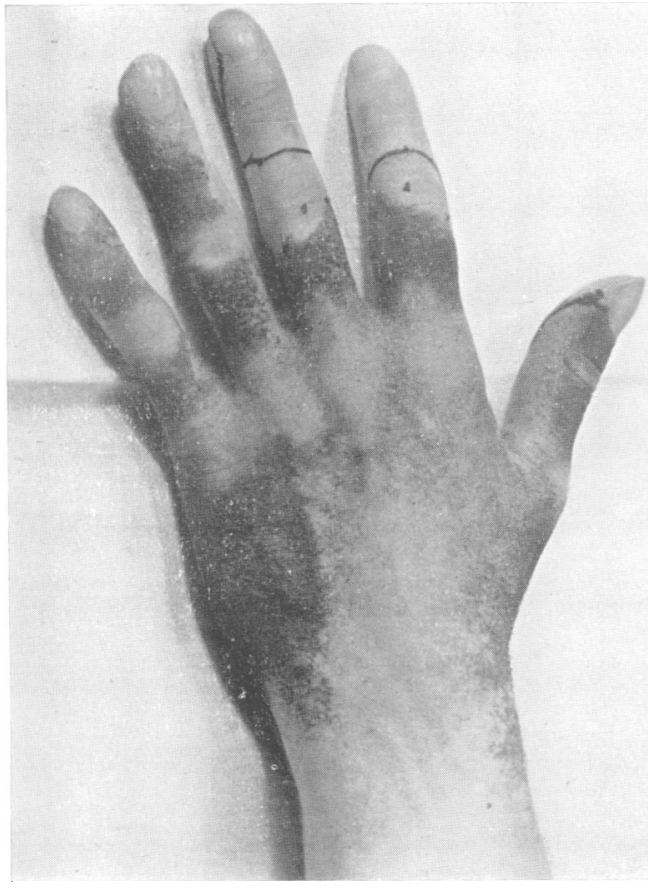

FIG. 8.

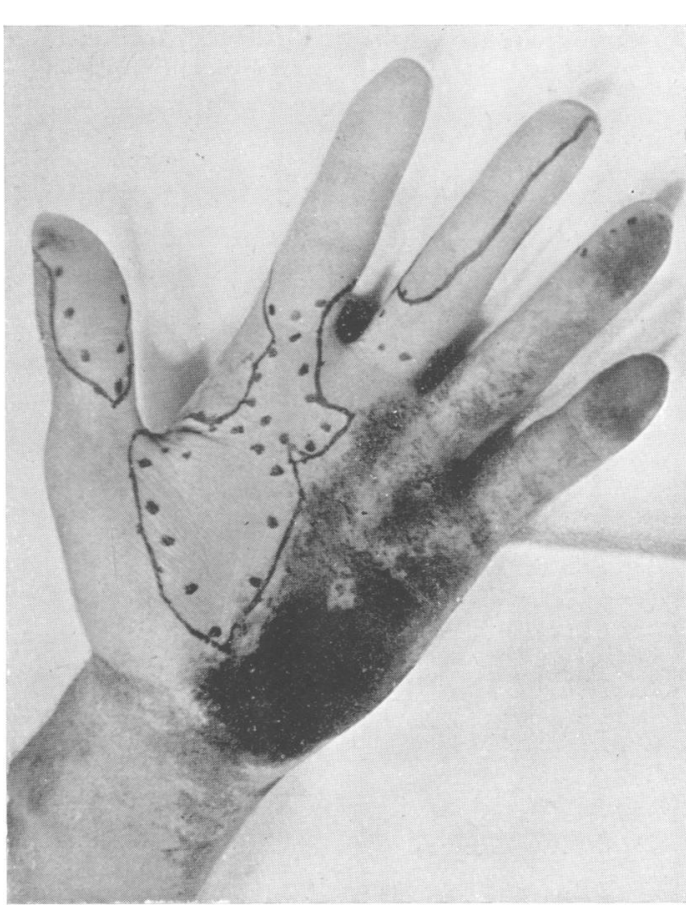

Fig. 7.

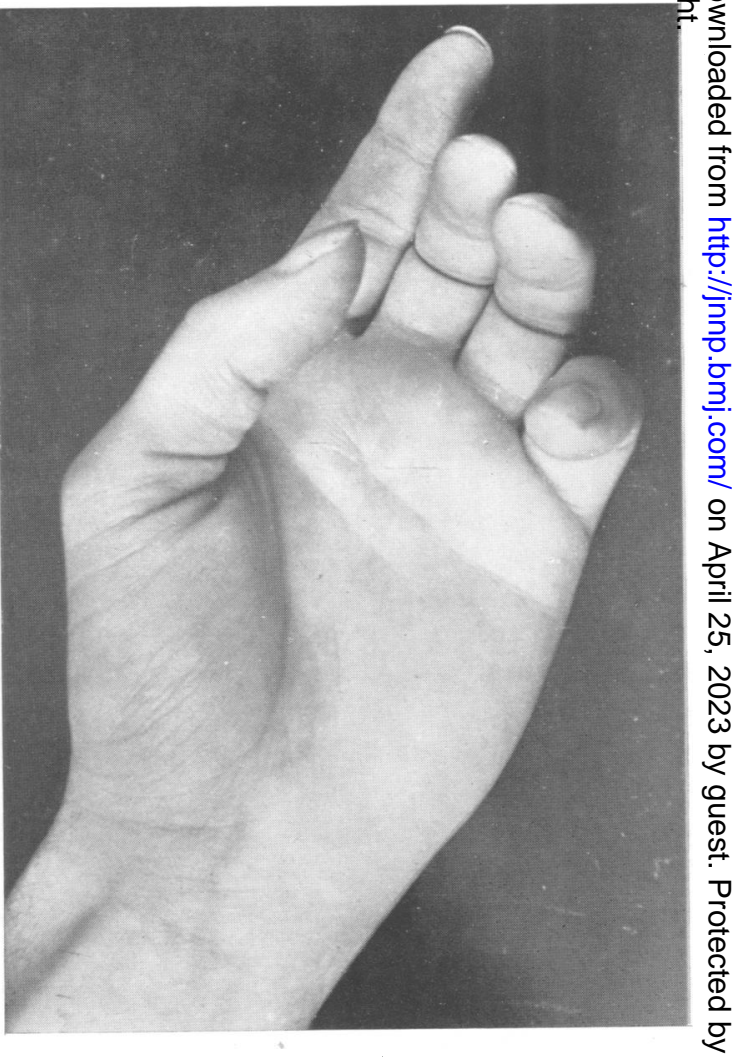

FIG. 9. 


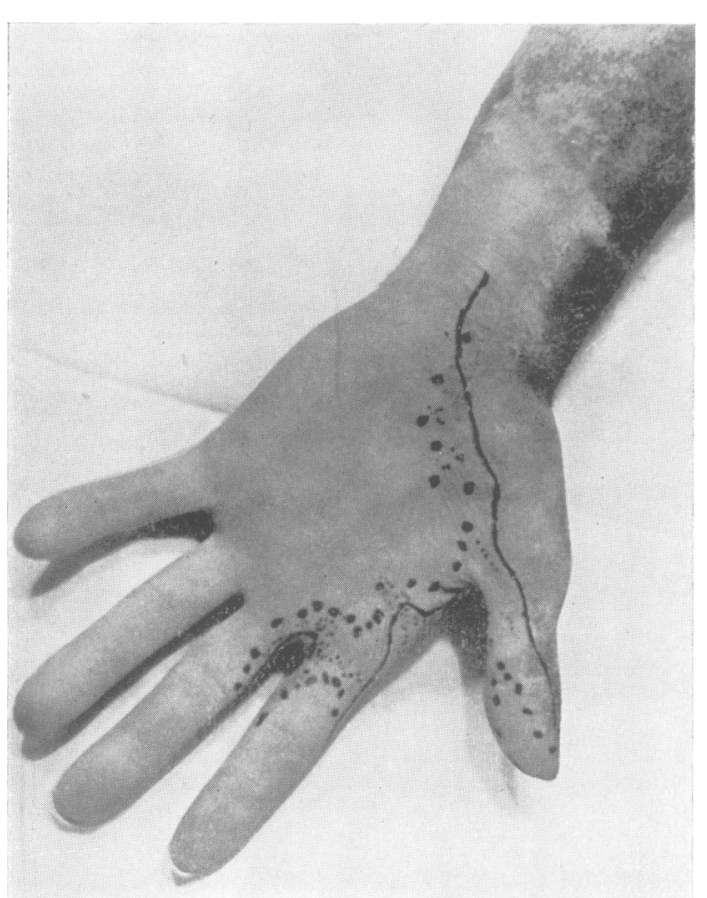

FIG. 10.

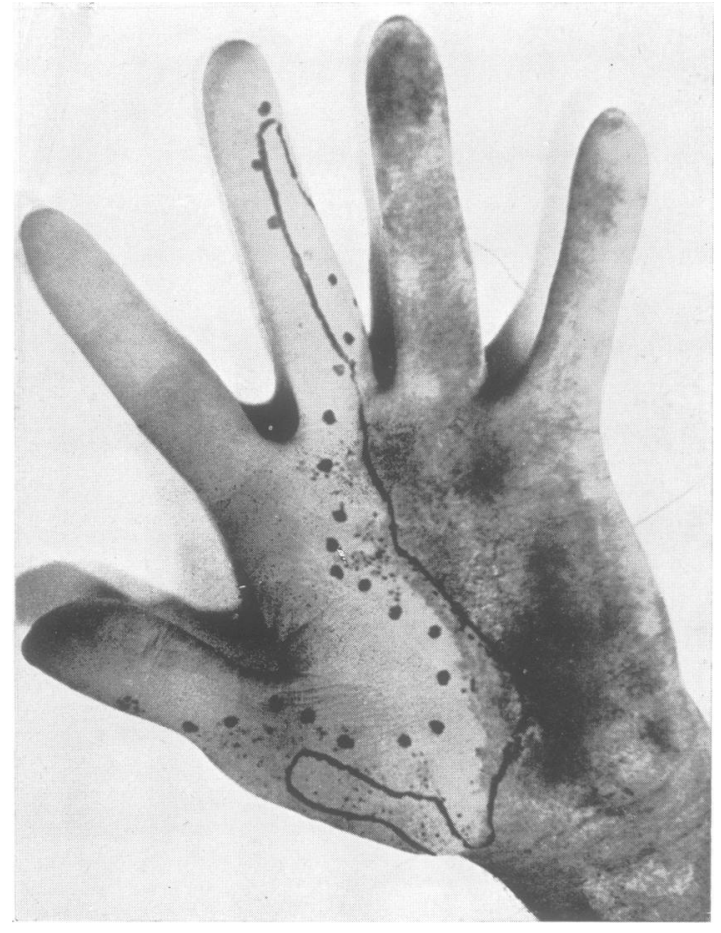

FIG. 12.

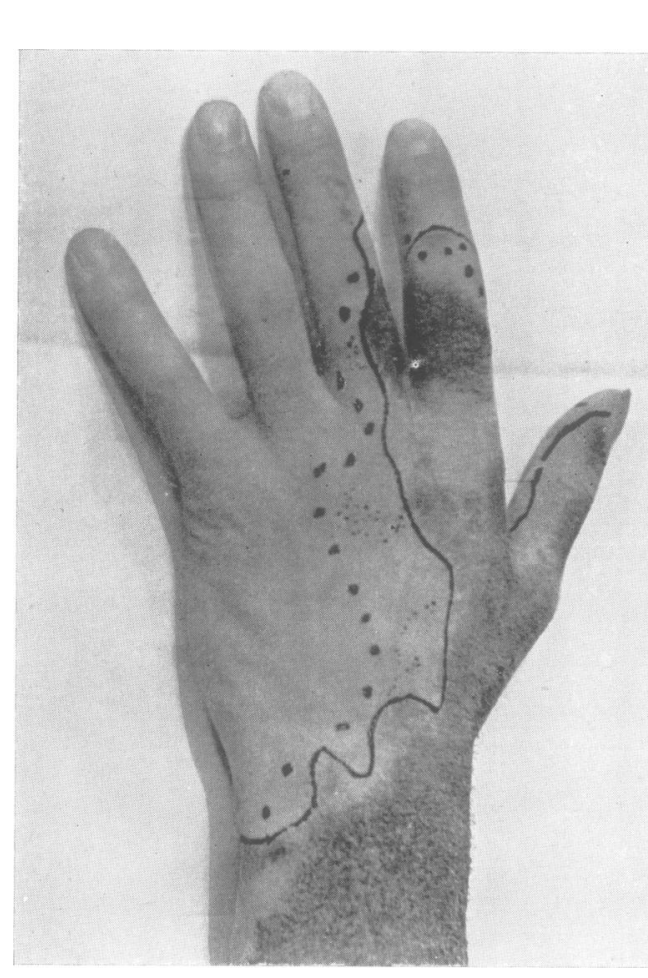

Fig. 11.

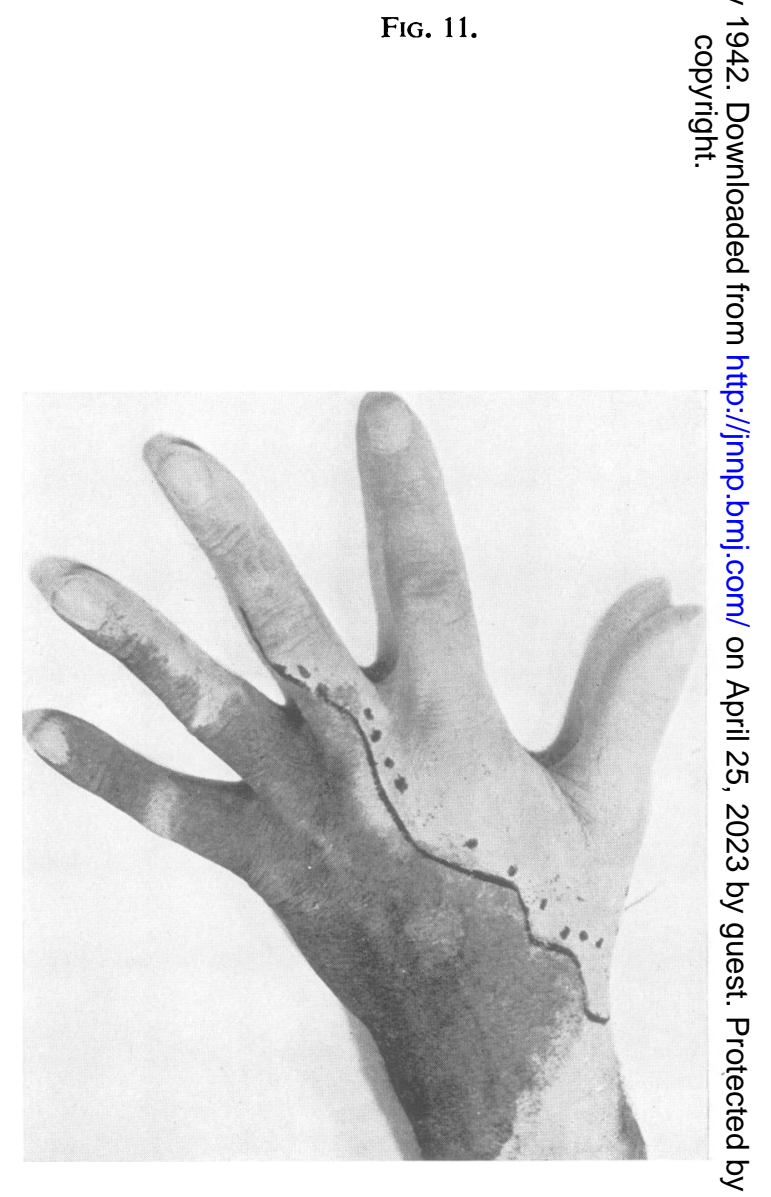

FIG. 13. 
sensory loss and loss of sweating. There is considerable overlap into the median area by both ulnar and radial nerves. Thus there is a complete band of pain sensibility over the metacarpo-phalangeal joints of the 1st, 2nd and 3rd digits and another band across the centre of the palm. There is no loss of sensibility or sweating on the 4th digit. Fig. 9 shows the complete paralysis of the thenar muscles (photographs during attempted opposition) after nerve block of the ulnar at the level of the medial epicondyle. Figs. 10 and 11 show the distribution of loss of sensation and sweating. The picture now represents a combined median and ulnar paralysis. The ulnar overlap is obliterated but the radial overlap is still evident over the metacarpo-phalangeal joints of the 1 st and 2 nd digits. This picture illustrates the maximal overlap by the radial nerve. Figs. 12 and 13 show the distribution of loss of sensation and sweating after nerve block of the radial (superficial radial nerve in the lower third of the forearm). The overlap of the radial nerve into the median area has been obliterated and the maximal overlap by the ulnar is shown. For instance, touch sensibility on the ulnar side of the 3rd digit is subserved by the ulnar. If Figs. 10 and 12

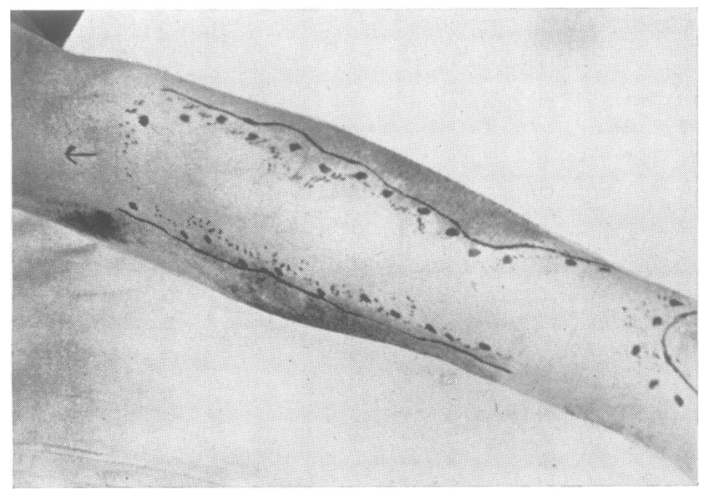

FIG. 14.

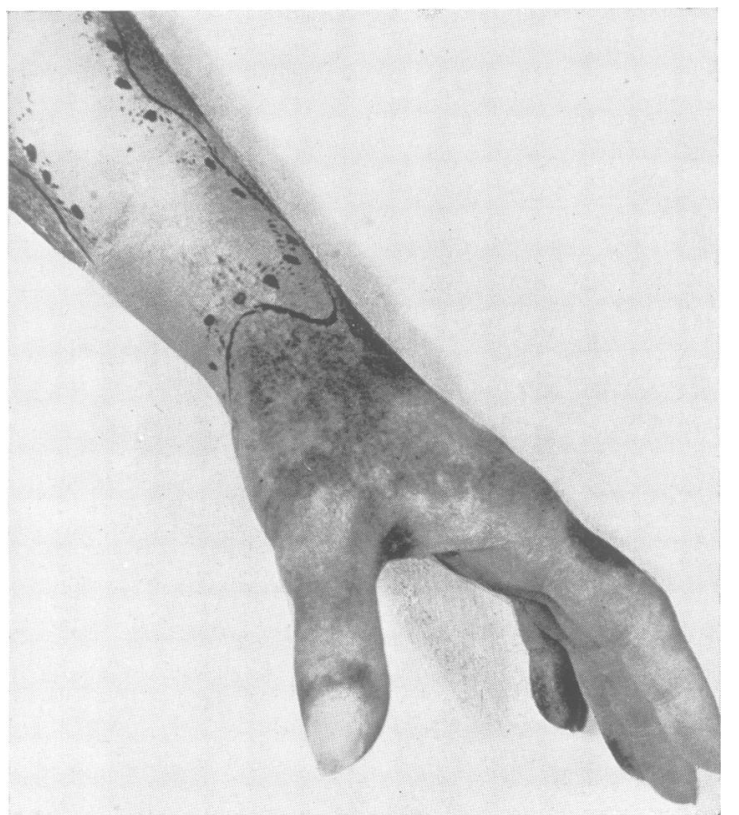

were superposed the resulting picture would be Fig. 7 . It may be noted that in Fig. 12 in spite of radial nerve block the lateral side of the thenar eminence has retained some touch and pain sensibility and slight sweating. This is due to overlap by the lateral cutaneous nerve of the forearm. Figs. 14, 15, and 16 show the distribution of loss of sensibility and sweating after nerve block of the lateral cutaneous nerve of the forearm (the site of block is marked by an arrow). In this series of pictures the whole area of median loss was not outlined, but only the margin of the area on the thenar eminence. Figs. 12 and 16 illustrate the overlap by the superficial radial and lateral cutaneous nerves of the forearm. Blocking of either nerve alone failed to abolish all sensibility and sweating over the lateral part of the thenar eminence which shows that this area was supplied by both nerves.

Case 2.-A case of injury to the median nerve at the wrist in which complete division was confirmed by operative exploration after the diagnosis had been established by nerve block. The nerve blocks were carried out when the patient was referred to us five months after the injury. In this case flexor brevis pollicis was active and innervated by the ulnar nerve. Fig. 17 shows the area of sensory loss. The area of anæsthesia and analgesia is rather small but outside the line of anæsthesia is a zone of hypoxsthesia (notched line). There is some touch and pain sensibility on the ulnar side of the 3rd digit and a band of pain sensibility across the base of the 2 nd digit and over the proximal phalanx of the thumb. Figs. 18 and 19 show the loss of sensibility and sweating after nerve block of the ulnar and radial nerves at the same session. The ulnar was blocked at the level of the medial epicondyle and the radial at the level of the spiral groove of the humerus. The picture represents a combined median, ulnar and radial paralysis It is obvious that the median lesion is complete, for there is now no sensation or sweating in the median area. Fig. 18 illustrates slight overlap onto the proximate part of the palm by one of the forearm nerves probably due to the medial cutaneous nerve of the forearm, but no attempt was made to prove this. Also Fig. 19 shows the overlap by the lateral cutaneous nerve of the forearm

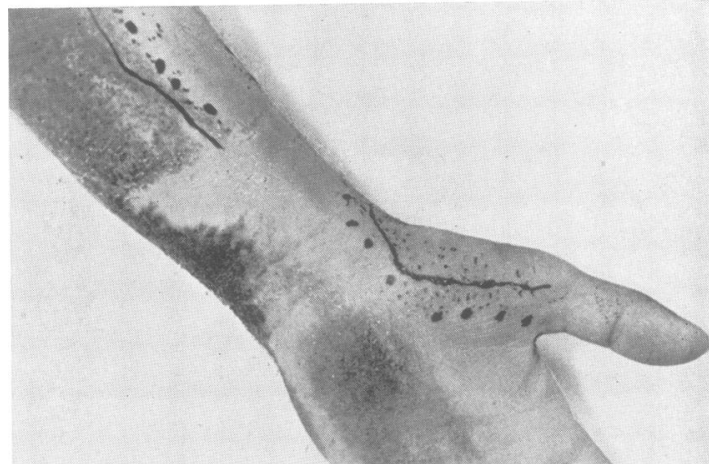

FIG. 16 
onto the metacarpal and dorsum of the proximal phalanx of the thumb.

Case 3.-This was a case of complete division of the ulnar nerve above the medial epicondyle, later proved by operative exploration. The nerve blocks were performed when the patient was referred to us 5 months after the injury.

Fig. 20 illustrates the action of flexor profundus digitorum to the 4th and 5th digits (referred to on page 102). Figs. 21 and 22 illustrate the loss of sensibility and sweating. The autonomous zone of the ulnar is unusually small and includes only the extreme tip of the 5th digit, the ulnar side and dorsum of the 5th digit and the ulnar side of the dorsum of the hand. The ulnar nerve was blocked a few centimetres above the level of the lesion. The sweating an sensory tests yielded findings identical with those shown in Figs. 20, 21, and 22. A few days later the median nerve was blocked in the antecubital fossa. The findings are shown in Figs. 23 and 24. There is now complete median and ulnar paralysis. The maximal zone of the radial nerve is illustrated on the dorsum of the hand. Fig. 23 also illustrates the

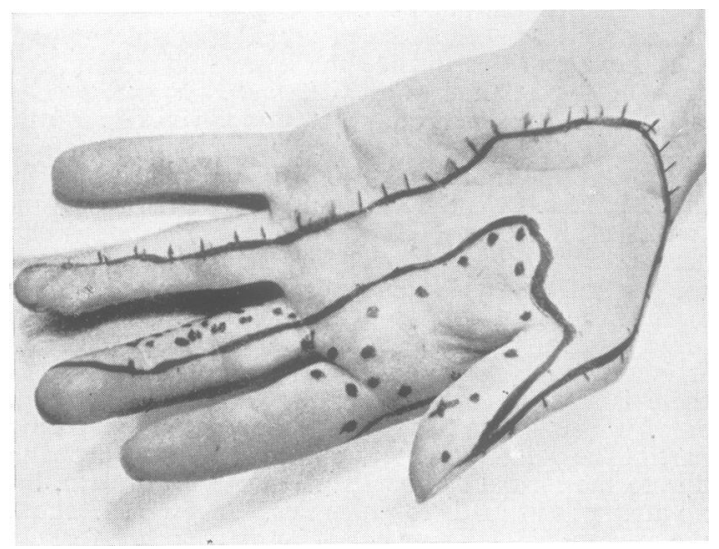

Fig. 17.

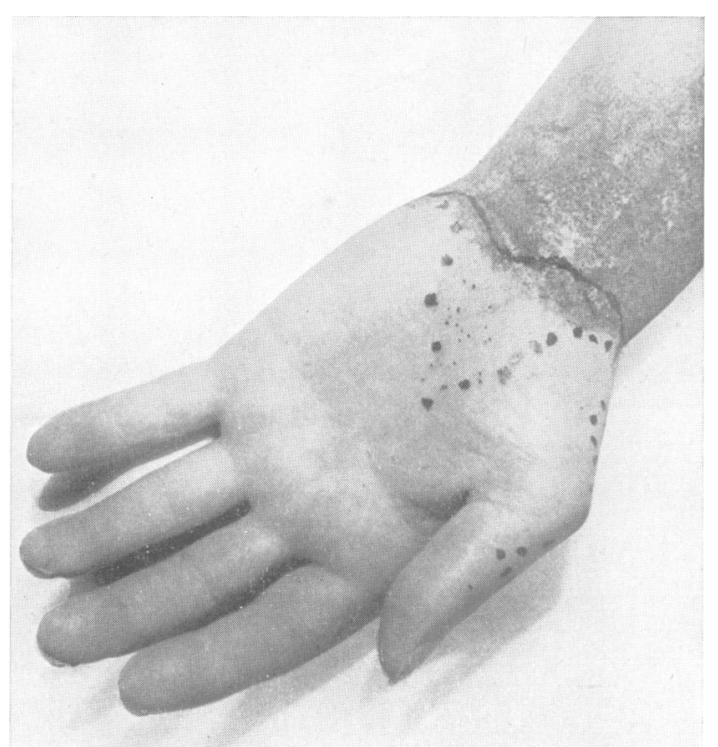

obliteration of all action in flexor profundus digitorum This nerve block confirmed the previous ulnar block and showed that the ulnar lesion was complete and that the small area of sensory loss and anhidrosis was due to extensive overlap by the median nerve.

Case 4.-This man sustained a traction injury of the upper trunk of the brachial plaxus- the injured segment was excised and a nerve graft inserted. The whole superficial radial nerve was excised for use as a graft.

Fig. 25 shows the loss of sensibility and sweating on the dorsum of the hand 3 weeks after operation. We were interested in the large tongue of sensibility and sweating extending from the dorsum of the forearm and into the superficial radial area. We thought it probable that this tongue was an extension of the dorsal cutaneous nerve of the forearm. Accordingly the radial nerve was blocked at the level of the spiral groove of the humerus just above the origin from the radial nerve of the dorsal cutaneous nerve of the forearm. Fig. 26 illustrates the area of loss of sweating and sensation after nerve block and shows that our surmise was correct.

Case 5.-This was a case of injury to the lateral popliteal nerve at the level of the knee. The area of loss of sensibility and sweating was typical except that there was a band of pain sensibility (marked by crosses) over the front of the leg just above the ankle and the area of loss on the dorsum of the foot was unusually narrow with an almost complete bridge of pain sensibility in the middle of the area, see Figs. 27 and 28 Nerve block of the lateral popliteal nerve was performed at the level of the neck of the fibula. The sensory and sweating pictures after nerve block were identical with the previous pictures. Thus the band of pain sensibility over the front of the leg was due to overlap by the saphenous and sural nerves and the small area of sensorg loss on the dorsum of the foot to overlap by the surat and medial plantar nerves. Complete division of the lateral popliteal nerve was confirmed by operative exploration.

Case 6.- In this case the ulnar and radial nerves were blocked, the ulnar at the level of the medial epicondyle and the radial at the level of the spiral groove of the humerus.

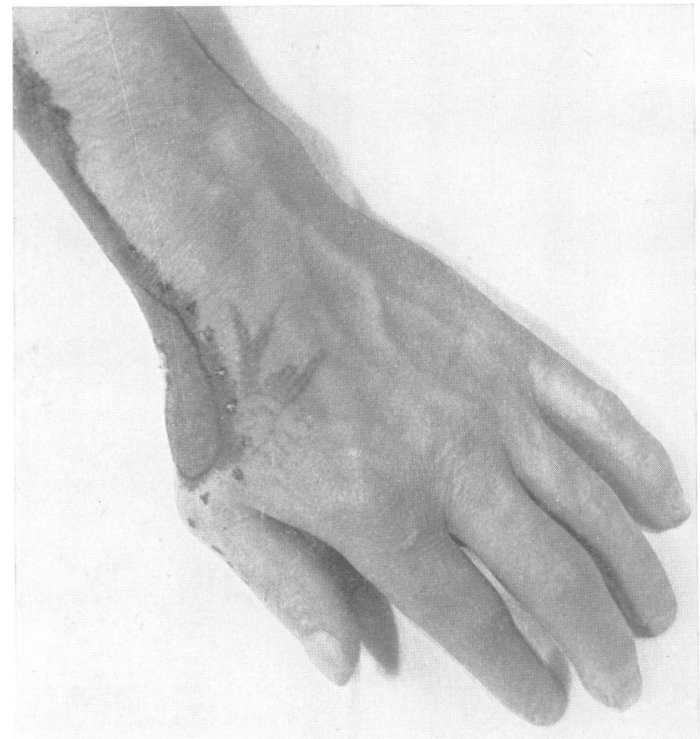

FIG. 18.

Fig. 19. 


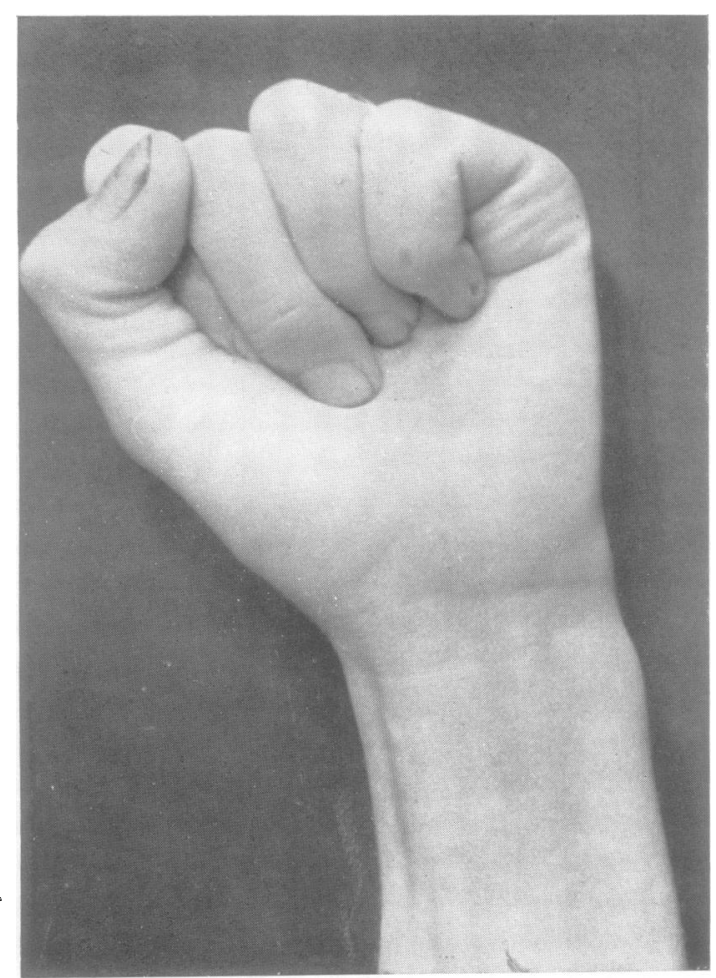

Fig. 20.

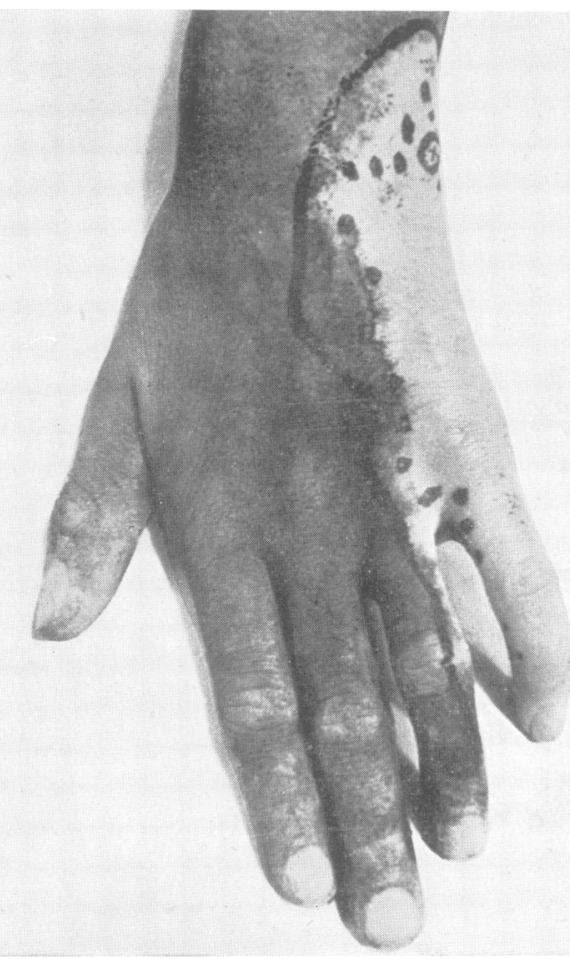

FIG. 22.

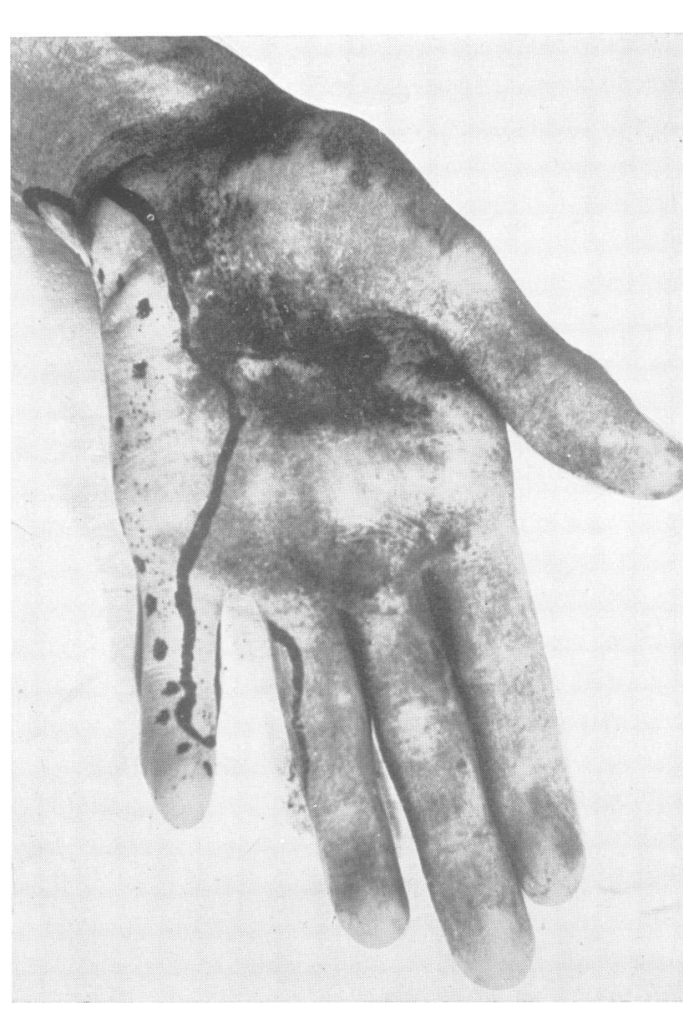

Fig. 21.

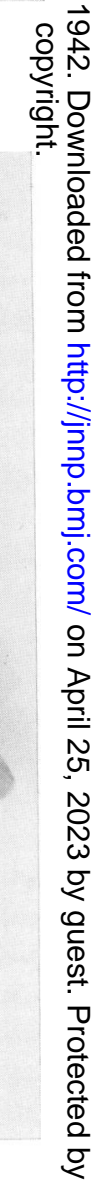

FIG. 23. 


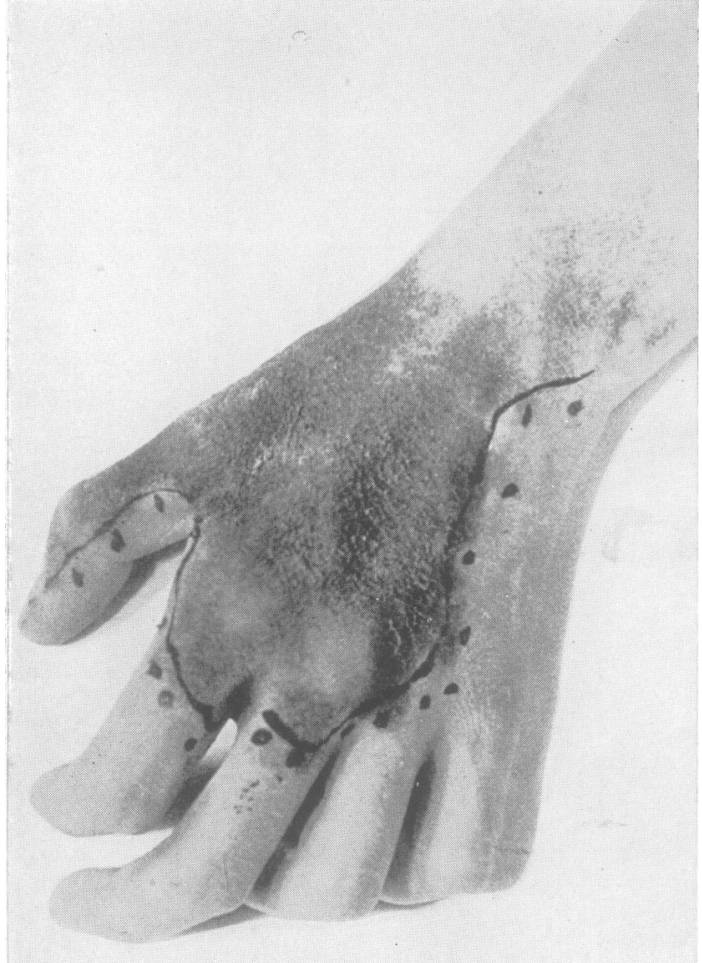

FIG. 24.

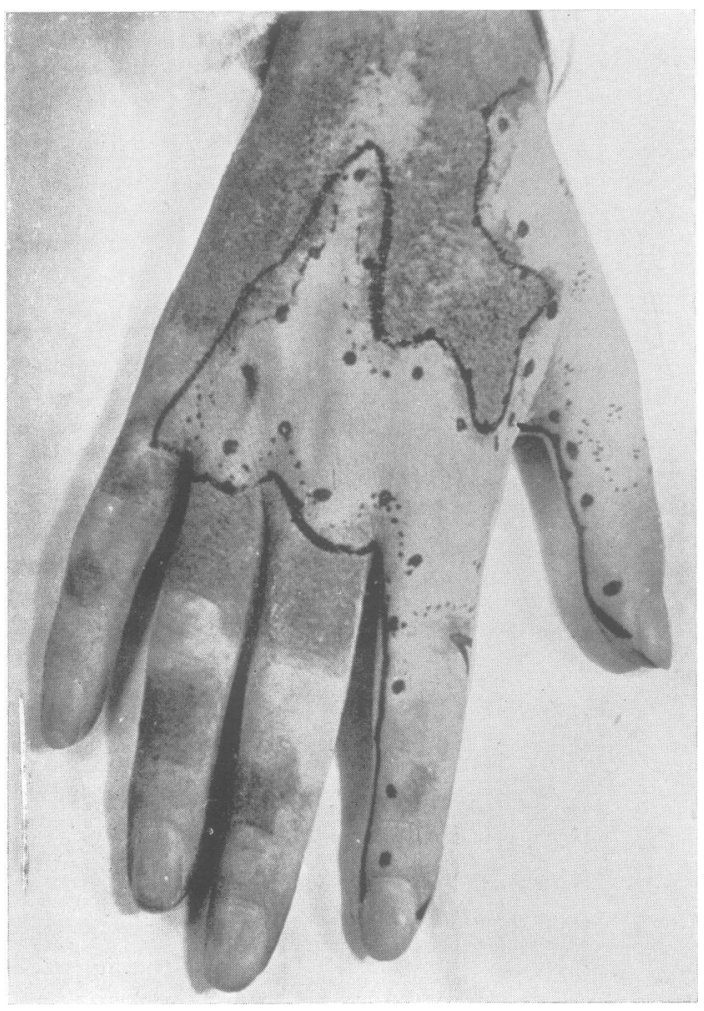

FIG. 26.

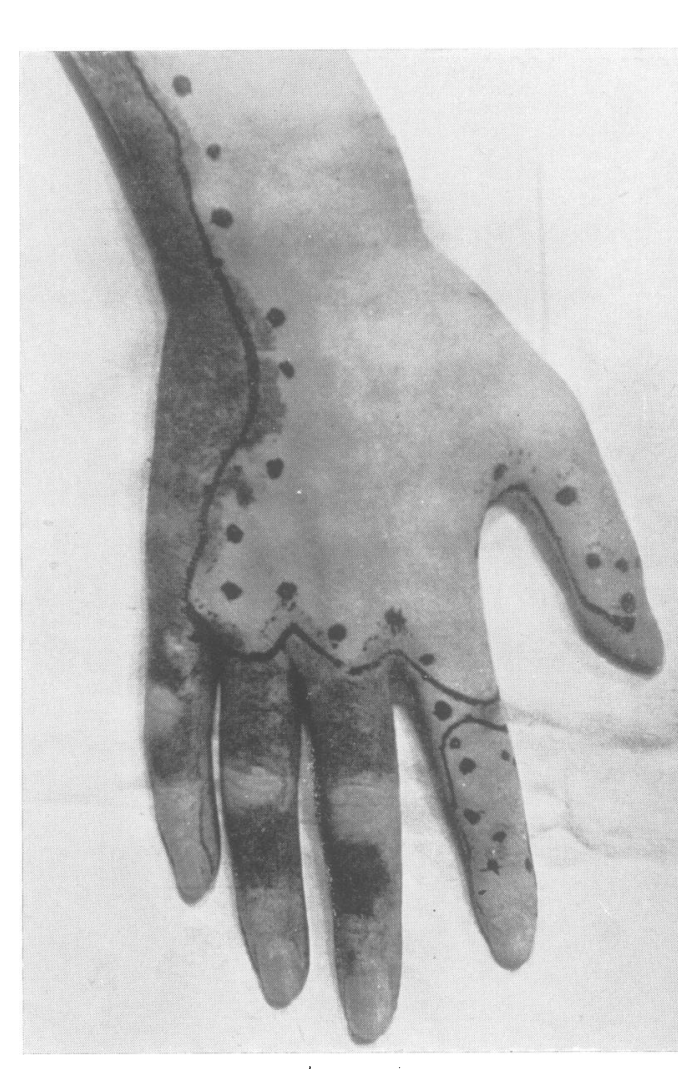

FIG. 25.

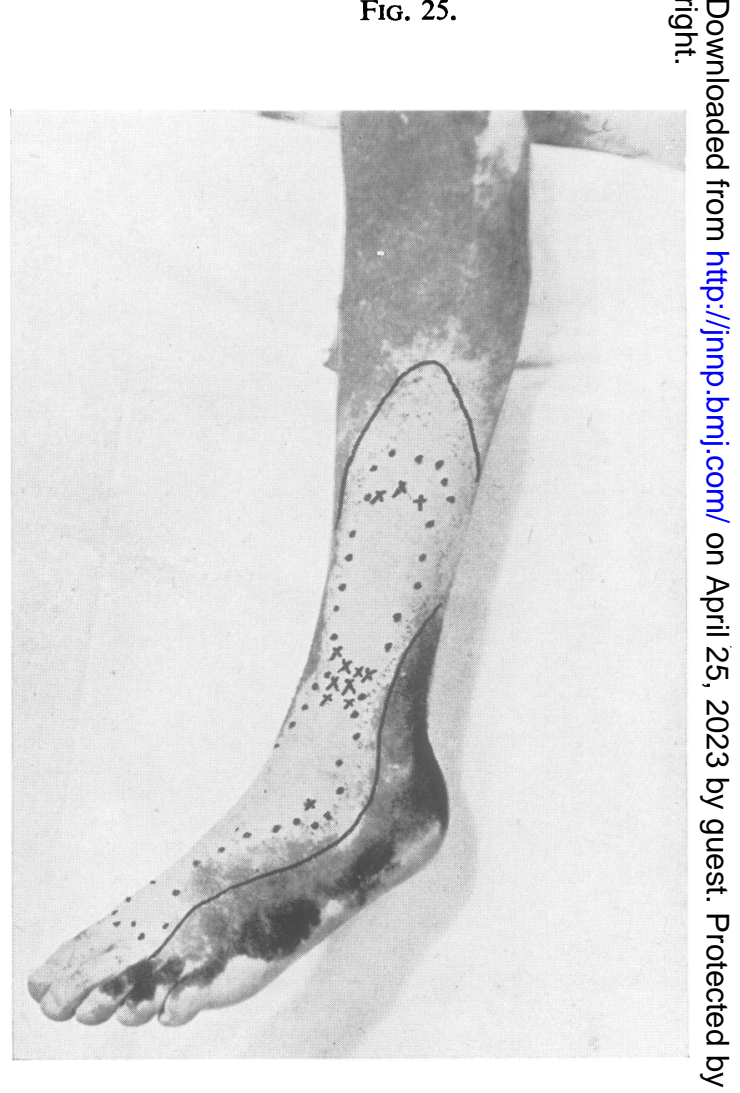

FIG. 27. 
Fig. 29 illustrates the maximal zone of the lateral cutaneous nerve of the forearm extending into the first interosseous space, the area which most text-books figure as innervated by the radial nerve. In this figure pain sensibility is not outlined. Fig. 30 illustrates the overlap by the lateral cutaneous nerve of the forearm

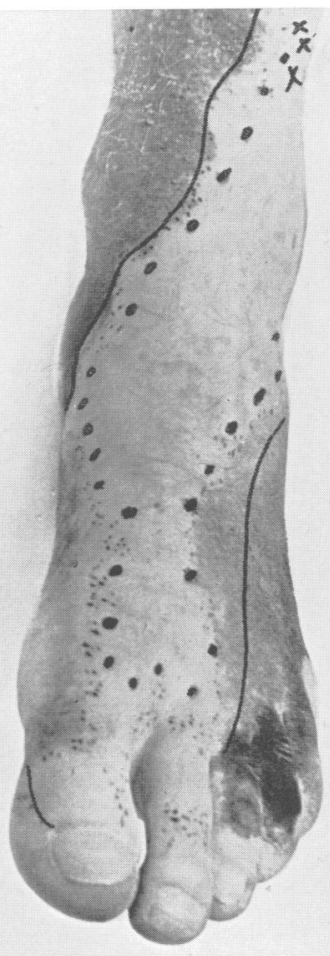

FIG. 28.

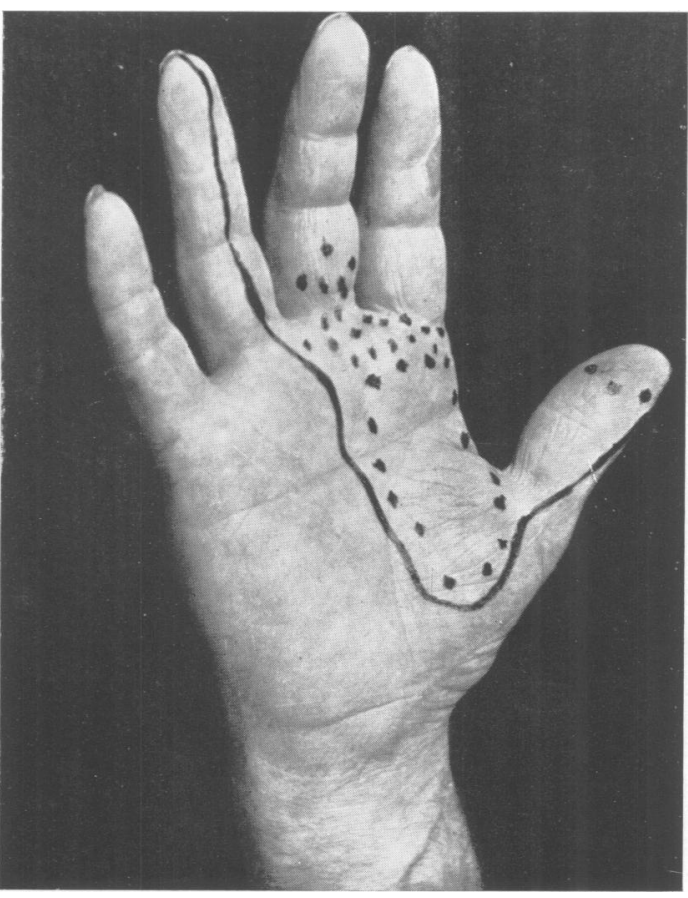

FIG. 31. into the superficial radial area in another case where both ulnar and radial nerves were blocked for another purpose.

Case 7.-In this case nerve blocks were carried out to differentiate true recovery from shrinkage by overlap.

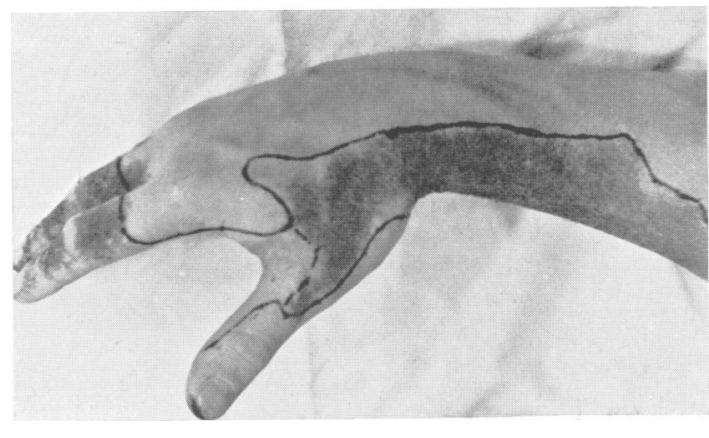

Fig. 29.

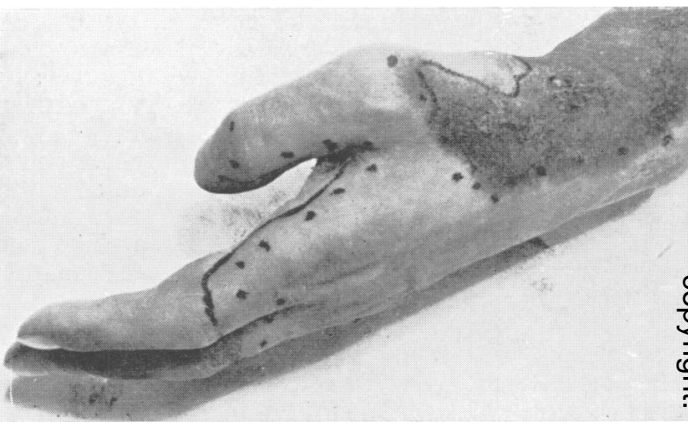

Fig. 30.

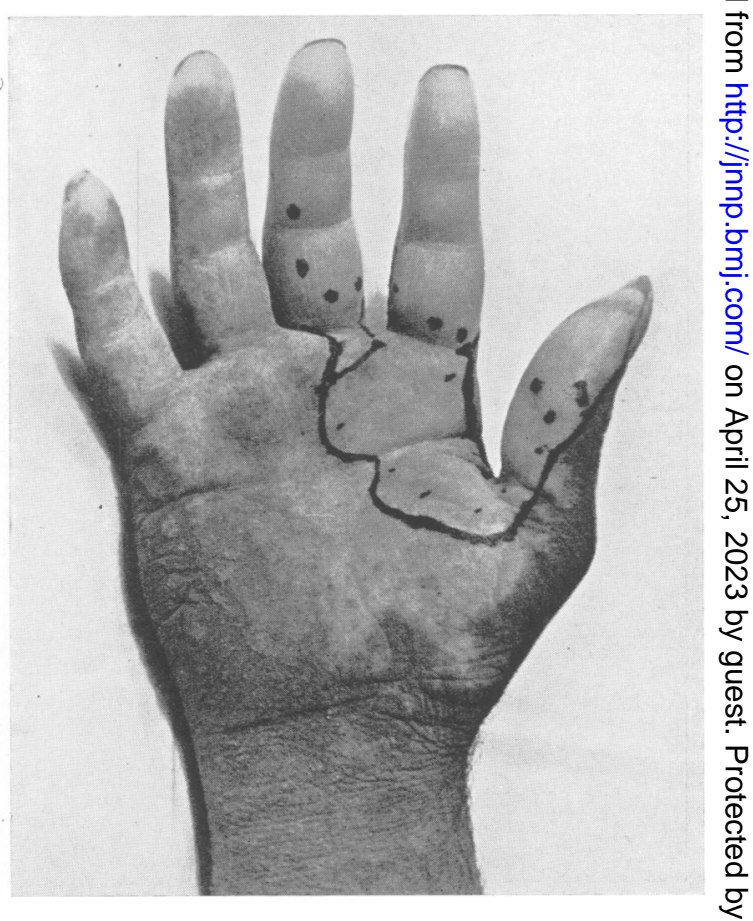

Fig. 32. 
Fig. 31 illustrates the area of sensory loss on 24/3/41, five months after division of the median nerve at the wrist $(28 / 12 / 40)$. Fig. 32 illustrates the area of loss of sensibility and sweating five months after suture of the median (11/9/41). There were fine pin-points of sweating over the median area in the palm and deep cutaneous pain was present, but not superficial cutaneous pain. We were uncertain whether this return of pain sensibility represented true recovery or shrinkage by overlap. Accordingly the ulnar and radial nerves were blocked at the one session. Fig. 33 illustrates the area of true recovery of pain sensibility in the median area (13/9/41). For clearness the pain dots have been joined up to enclose the area of recovery.

Case 8.-This case illustrates the use of nerve block in the differentiation of true regeneration from shrinkage by overlap of neighbouring nerves. This was a case of complete division of the median and ulnar nerves in the mid arm. Suture had been performed elsewhere. Figs. 34 and 35 illustrate the disturbance of sweating and sensibility on 6/5/41. Fig. 36 shows the presence of some deep cutaneous pain (crosses) extending into the median area over the thenar eminence and radial side of the palm (17/7/41). Fig. 37 shows an advance of pain sensibility, chiefly deep cutaneous pain $(2 / 2 / 42)$, beyond that shown in Fig. 36. We were uncertain whether this was due to true regeneration or to overlap by the adjacent radial nerve. Fig. 38 illustrates the condition after nerve block of the radial nerve at the level of spiral groove of the humerus. The pain sensibility over the radial side of the palm and over the thumb is still present and represents recovery in the median nerve and as the measure shows, an advance of $13 \mathrm{~cm}$. distal to the wrist.

It is noteworthy that recovery has taken place chiefly in the part of the median area adjoining the area supplied by the intact radial nerve.

Case 9.- This was a case of injury to the median nerve. He was referred to us 18 months after the injury. The area of sensory loss is illustrated in the right-hand part
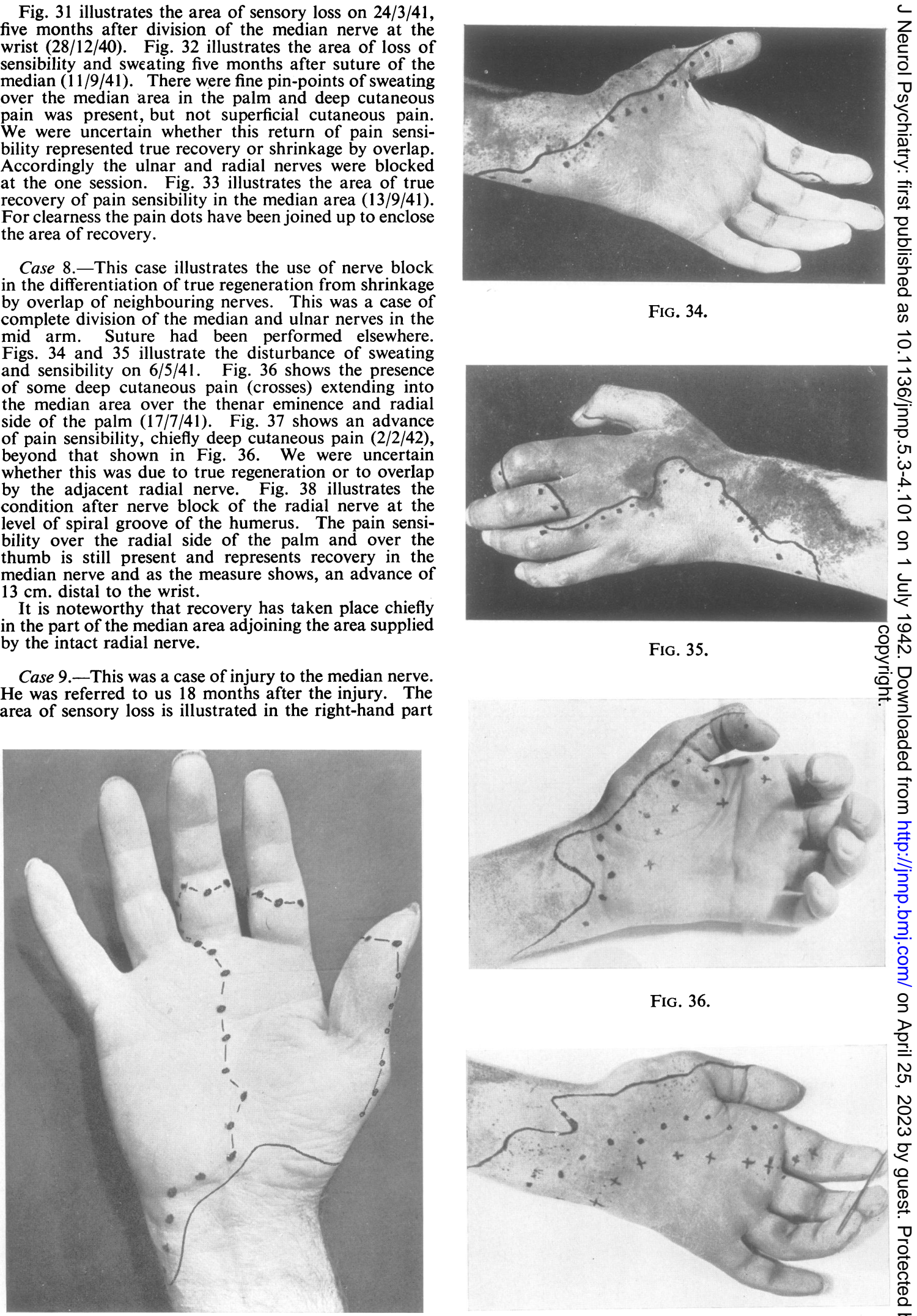

FIG. 34.

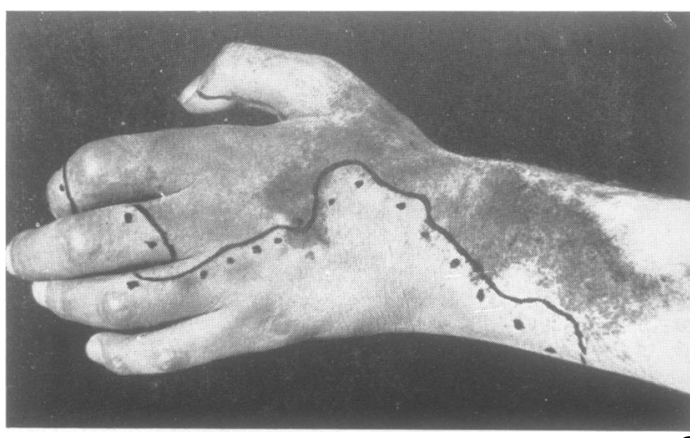

FIG. 35.

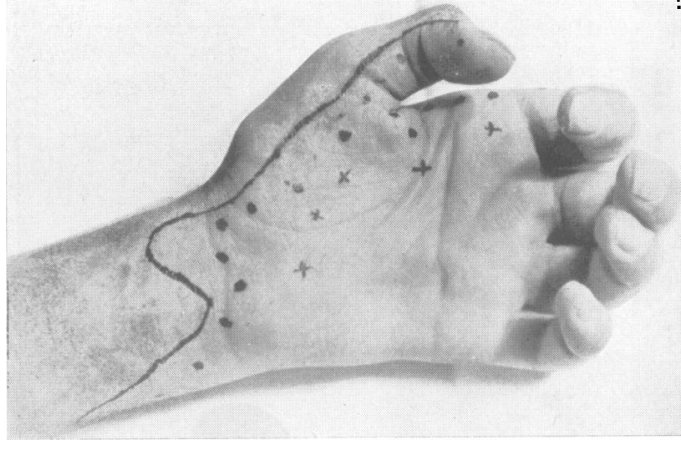

FIG. 36.

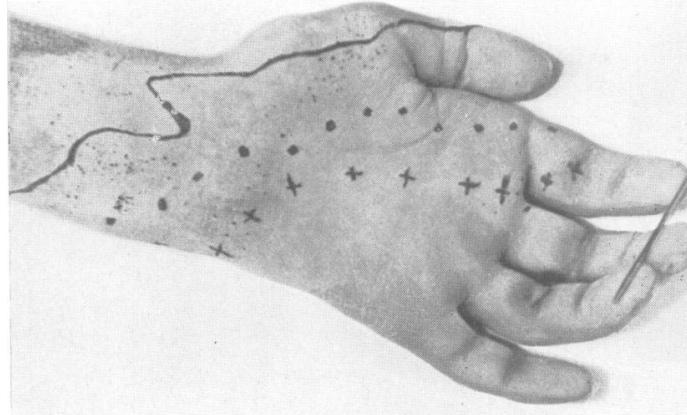

FIG. 33.

FIG. 37. 
of Fig. 39. There was complete analgesia of the tip of the thumb and the whole of the index finger, but no analgesia on the middle finger or over the palm. Anæsthesia was confined to the radial $2 \frac{1}{2}$ digits. The problem in this case was whether this sensory loss indicated a small autonomous zone after complete division of the median or a sensory loss due to incomplete division of the median. Accordingly the ulnar nerve was blocked at the level of the medial epicondyle. The resulting sensory loss of ulnar distribution is illustrated in Fig. 39. There was a broad band of touch and pain sensibility between the median and ulnar areas. The nerve block indicated that the median lesion was incomplete.

To confirm this a second nerve block was performed 2 days later. The median nerve was blocked. Fig. 40 shows the area of anæsthesia and analgesia thus obtained. The area of median sensory loss now involves the classical area.

At operative exploration a few days later incomplete division of the median nerve was disclosed. There was a well-marked lateral neuroma at the site of injury.

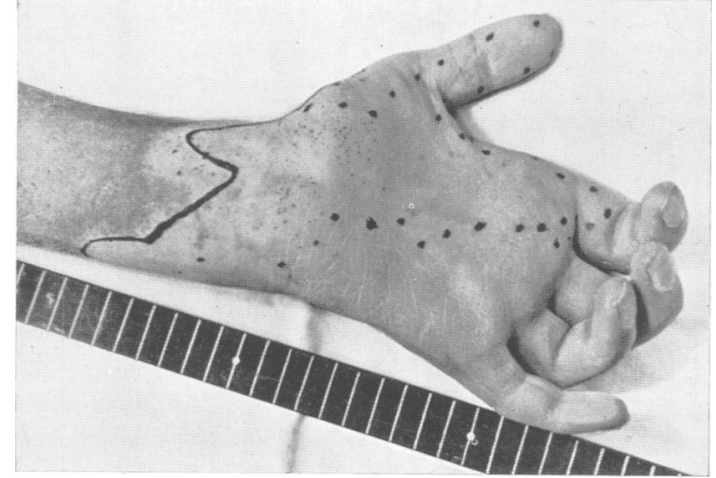

FIG. 38 .

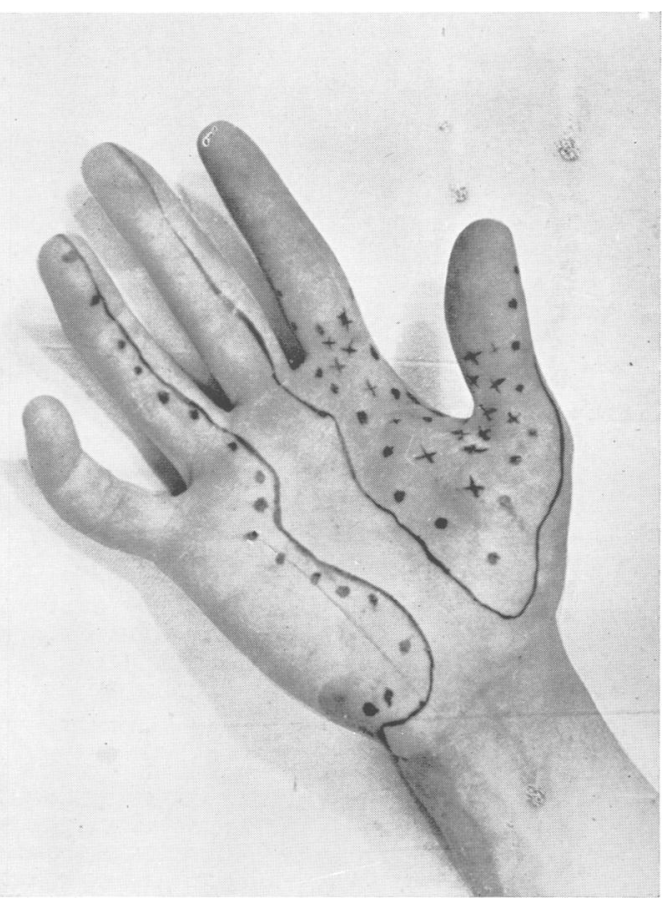

Fig. 39.
Case 10.-This was a case of injury to the median and radial nerves in the axilla. Fig. 41 illustrates the area of loss of sensibility and sweating in the hand. The area of analgesia on the front of the hand is unusually small and analgesia is limited to the index finger and thumb. As in Case 9 the question arose whether this was a case of complete or incomplete division of the median. Accordingly ulnar nerve block was performed at the level of the medial epicondyle. Fig. 42 shows the result of a sweating and sensory test after the nerve block. All sweating and sensibility has been abolished in the hand. Thus the small area of median sensory loss in Fig. 41 is due to extensive overlap into the median area by the ulnar nerve. At operative exploration the median nerve was found completely divided.

Case 11.-This case illustrates the value of nerve block in the investigation of dissociated paralysis. This was a case of transient block of the radial nerve due to crutch palsy. When he was referred to us five days after the onset of the paralysis there was complete paralysis of all

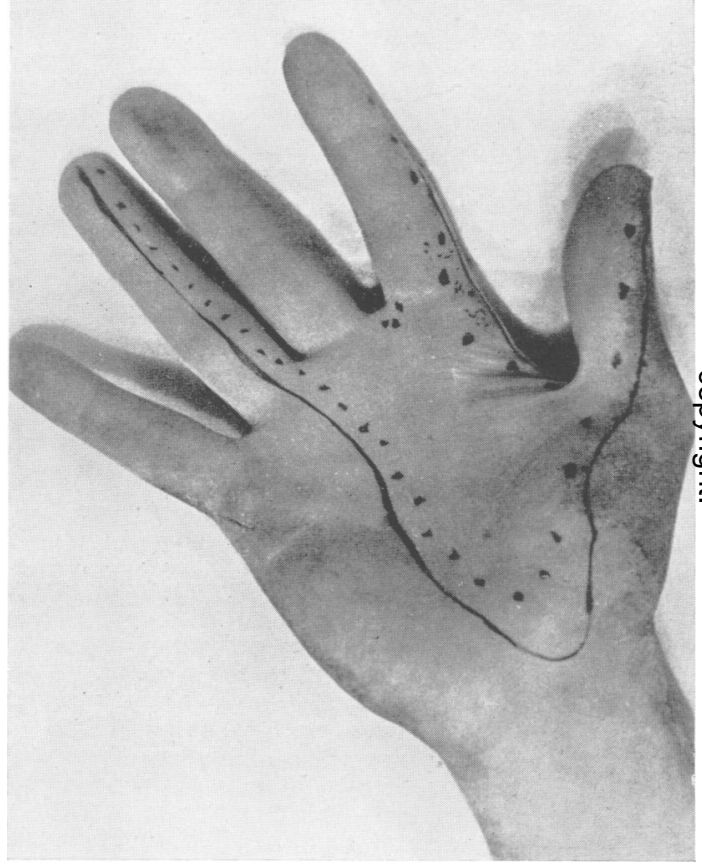

Fig. 40.

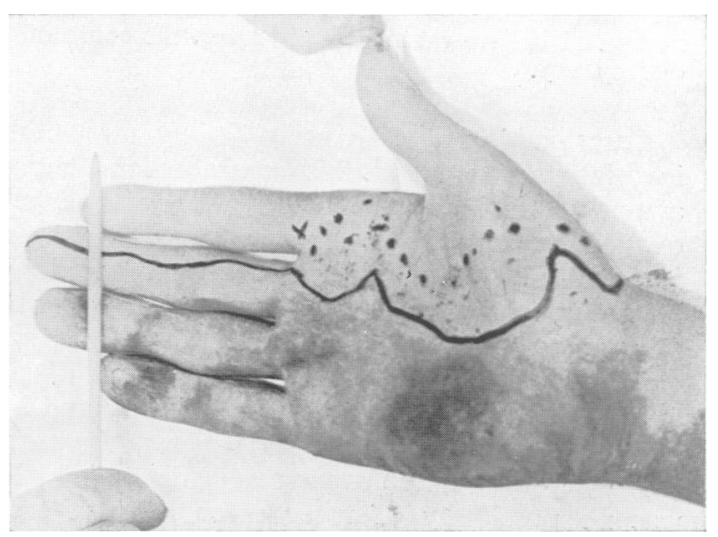

FIG. 41. 
muscles of radial innervation, including triceps. As in all cases of transient block the muscles retained their faradic excitability. There was no loss of sensibility or sweating. Neurapraxia is one type of dissociated paralysis in which, though there is complete loss of voluntary power in the muscles supplied by the injured nerve, there is usually very slight or no detectable disturbance of sensibility and sweating. To prove that this was a case of dissociated paralysis the radial nerve was blocked at the level of the spiral groove of the humerus. The sweating and sensory tests shown in Fig. 43 show that there is now loss of sensibility and sweating over the whole distribution of the radial nerve, the areas supplied by the lower lateral cutaneous nerve of the arm, the dorsal cutaneous nerve of the forearm and the superficial radial.

Case 12.-This case illustrates the shrinkage of the area of sensory loss by overlap of neighbouring nerves. In this case I produced an experimental lesion in continuity of the lateral cutaneous nerve of the thigh in a volunteer. Accurate sensory and sweating tests were performed at frequent intervals in order to investigate the process of sensory regeneration. Full details of the investigation are to be published at a later date.

On $14 / 3 / 41$ the lateral cutaneous nerve of the thigh was exposed under local anæsthesia and forcibly crushed with artery forceps. Complete axonotmesis was produced at a level just below the anterior superior iliac spine. Fig. 44 shows the area of loss of sensibility and sweating on $3 / 4 / 41$. Only the lower part of the area is shown in this and in the subsequent pictures. The noteworthy feature is the small size of the intermediate zone. Unfortunately nerve block was not performed before operation, but Fig. 45 illustrates the area of loss of sensation and sweating after nerve block of the corresponding nerve of the opposite leg. As in Fig. 44 the intermediate zone is of very small extent. Fig. 46 shows the sensory and sweating disturbance on $6 / 6 / 41$ before any true regeneration was possible to this level. The intermediate zone shows a considerable enlargement. Sweating and pain sensibility now extend well within the touch line.

On $8 / 5 / 42$ pain sensibility had recovered over the whole area and there was also some sweating over the whole area. Nerve block was performed and was certainly complete. Fig. 47 shows the area of loss of sweating and sensibility after nerve block. The intermediate zone is larger than in Figs. 44 and 45.

This nerve block shows that after recovery took place in the injured nerve the hyperactivity of the neighbouring nerves was still evident-in other words, that the signs of shrinkage by overlap from neighbouring nerves were still present.

I have noted repeatedly that the area of sensory loss and anhidrosis after nerve block of normal nerves is usually more extensive than the corresponding area encountered in cases of complete division of peripheral nerves. I believe that Case 12 reveals the cause of this discrepancy.

Cases of peripheral nerve injury are almost invariably referred to this centre several months after the original injury. By this time shrinkage by overlap has already taken place so that the area is less extensive than immediately after the injury. However, in several cases to be reported elsewhere (Guttmann and Highet, 1942) we have been sufficiently fortunate to be able to carry out detailed examinations immediately after the injury and have demonstrated a progressive shrinkage of the area of sensory loss by nerve overlap at a time when there was no possibility of true recovery by regeneration.

The above cases, however, illustrate the difficulty in making a clinical distinction between shrinkage $\frac{c}{z}$ by overlap and the early stages of true regeneration.

Investigation of the Vasomotor Distribution of $\underline{O}$ Peripheral Nerves

When a peripheral nerve containing sensory $\stackrel{?}{\supset}$ fibres is completely anæsthetized full vasodilatation occurs in the area of skin supplied by it. In the course of various planocaine nerve blocks I have $\overrightarrow{\vec{\omega}}$ made recordings of skin temperature with thermocouples. The investigation of vasomotor paralysis in injured nerves is not yet completed, but my impression is that the distribution of vasomotor $\mathbb{D}$ fibres is identical with the distribution of unmyeli- $\frac{2}{8}$ nated fibres subserving sweating and pain. In this connection I have investigated only the median, $\vec{\circ}$ ulnar, and radial nerves. After nerve block of $\vec{\overrightarrow{ }}$ normal nerves full vasodilatation takes place over $\vec{\omega}$ the 5th digit and almost full vasodilatation over $\vec{\partial}$ the 4th digit. After nerve block of injured nerves vasodilatation takes place only in the areas which or have preserved some sweating and pain sensibility. Also in recovering nerve lesions vasodilatation takes place only in the areas which have recovered sweating and pain sensibility.

Sympathetic Nerve Block in the Investigation of $\underset{\text { Causalgia }}{\stackrel{\vec{c}}{<}}$

There is a growing tendency to refer causalgic $\vec{\bullet}$ pain to some disturbance of the peripheral symp\& $\frac{0}{\mathrm{~N}}$ thetic system. The following case illustrates the use of sympathetic block in this connection.

Case 13.-On 26/8/40 a woman aged 27 sustained a bomb splinter injury of the left thigh. A fragment injured the sciatic nerve in the mid thigh. For a few days only there was a sciatic paralysis. Within half an hour of the injury she complained of severe burning pain over the whole foot. The pain was accompanied by increased sweating in the foot and by severe emotional disturbance. On 12/11/40 peri-arterial sympathectomy was performed at another hospital. The femoral artery was exposed in Hunter's canal and the adventitis injected with absolute alcohol. This operation had no effect on the pain. On 17/7/41 she was admitted to the Wingfield-Morris Orthopædic Hospital. There was no motor paralysis or sensory loss, but the whole sole 3 and part of the dorsum of the foot showed marked over-response to tactile and painful stimuli. She still complained of spontaneous burning pain and was unable to walk on account of the tenderness of the sole of the foot. The skin temperature of the whole of the left foot was increased $3^{\circ} \mathrm{C}$. as compared with the normal foot.

On $29 / 7 / 41$ the left lumbar sympathetic chain was infiltrated with 30 c.c. 1.5 per cent. procaine with $1 / 30,000$ adrenalin. At the time of the injection the patient was weeping and miserable. Within 10 minutes of the injection she sat up and smiled and volunteered the information that her pain had completely disappeared and that the foot had never been so comfortable. Tem- $\underset{\gamma}{\sigma}$ perature recordings showed full vasodilatation of the left foot. Two hours after the injection the pain returned and within four hours of the injection had reached its former intensity.

On $30 / 7 / 41$ neurolysis of the sciatic nerve was performed. There was a band of scar encircling the nerve at the level of the mid thigh but the nerve itself appeared normal except for a slight area of induration of the medial popliteal component. This operation had no effect on her pain, in fact, the pain and over-response to stimuli showed a marked increase. 


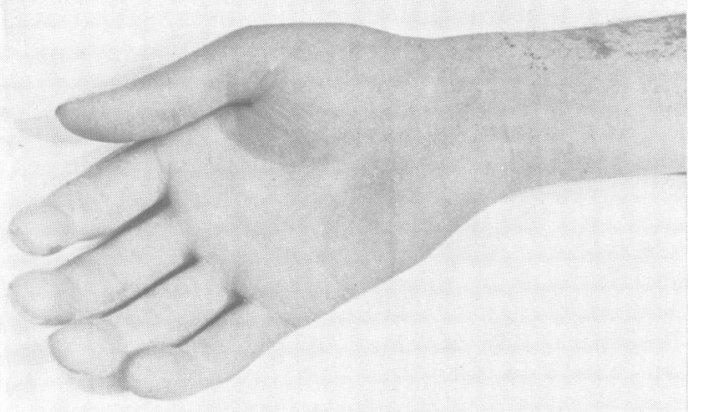

FIG. 42.

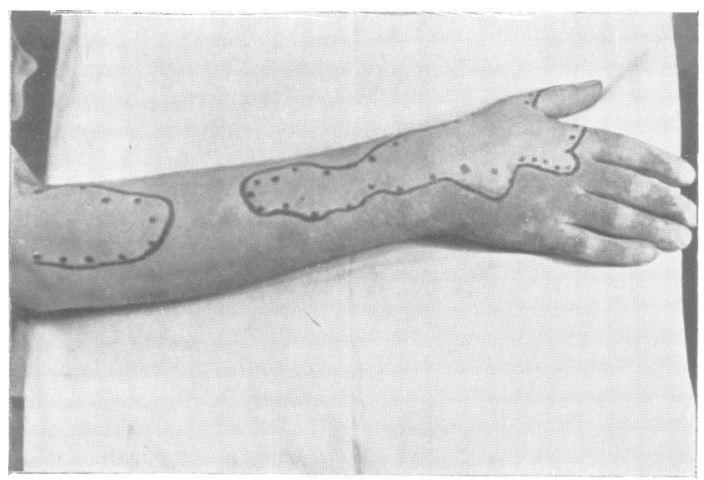

FIG. 43.

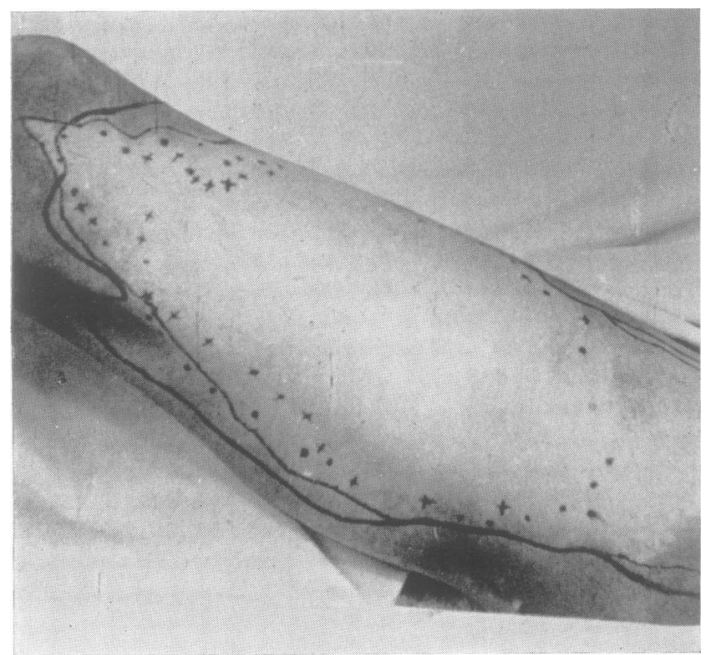

Fig. 44.

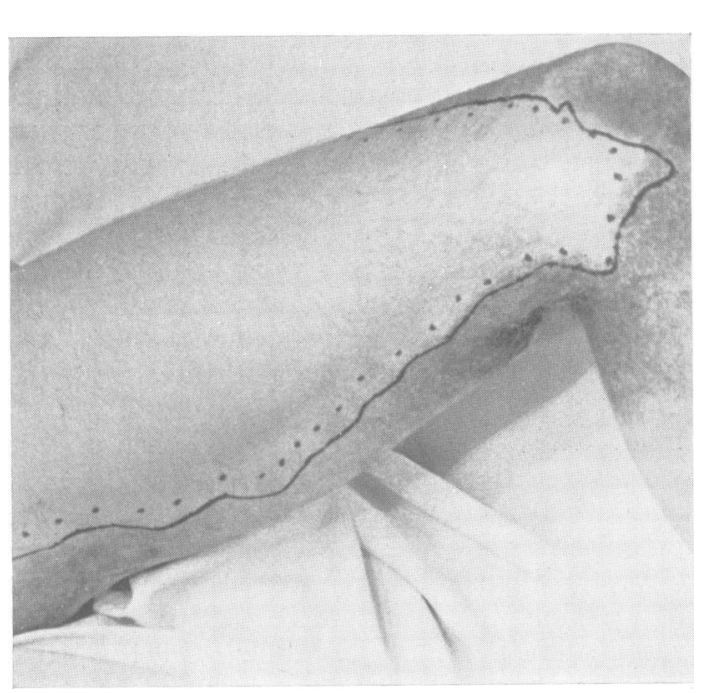

Fig. 45.

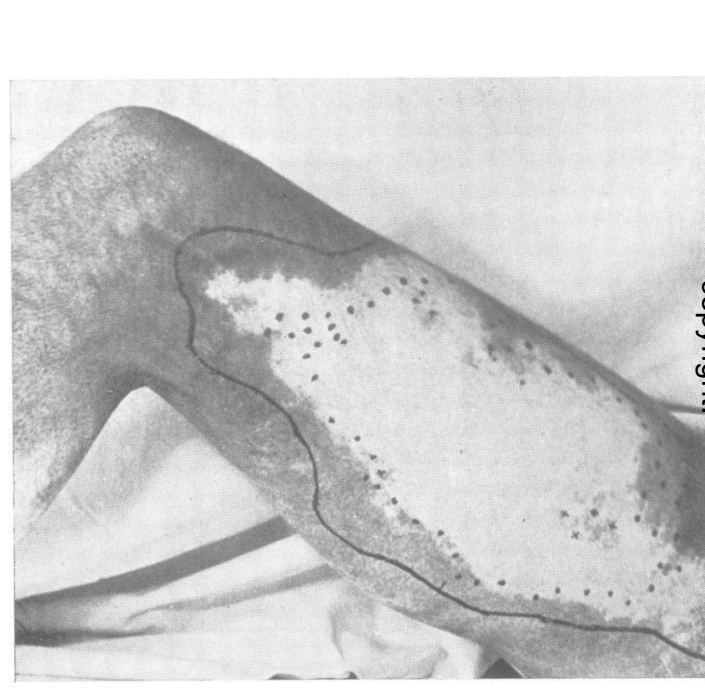

FIG. 46.

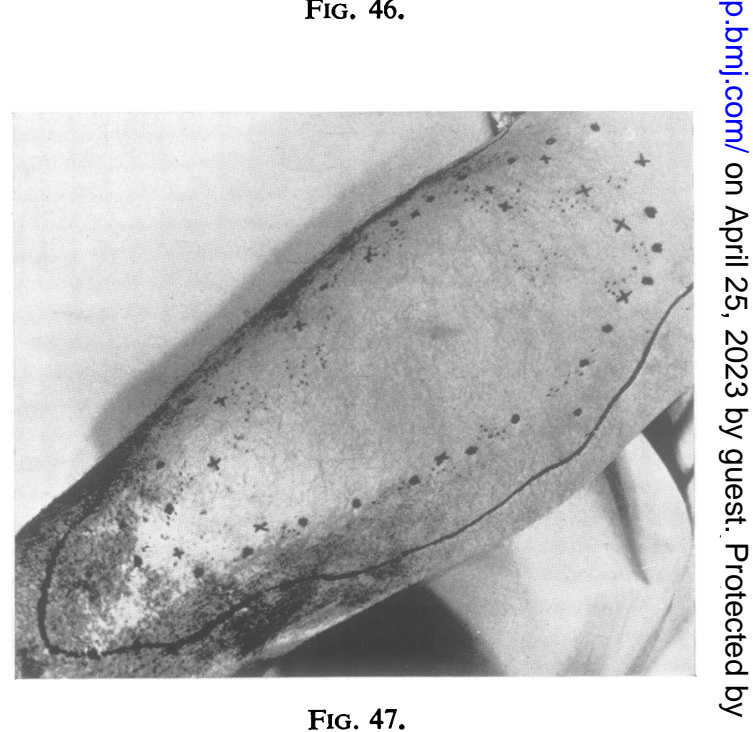

Fig. 47. 
Before proceeding to lumbar sympathectomy certain controlled observations were made. An attempt was made to produce full vasodilatation of the legs by immersion of the arms and upper part of the trunk in a hot-air chamber-the legs were left exposed to the room temperature. Reflex vasodilatation occurred in both feet, but the pain in the left foot rapidly became intolerable. In other words, reflex vasodilatation, far from relieving the pain, seemed only to increase it. On 14/9/41 the left lumbar sympathetic chain was again subjected to paravertebral injection. The chain was first infiltrated with normal saline. This had no effect whatever on her pain. The needle was left in situ and twenty minutes later 30 c.c. of 1 per cent. procaine was injected. As on the previous occasion $(29 / 7 / 41)$ all pain disappeared within 10 minutes of injection. Temperature recordings showed full vasodilatation of the left foot. On 17/9/41 left lumbar sympathectomy was performed with removal of the 2nd, 3rd, and 4th lumbar ganglia and the intervening sympathetic chain.

Since operation she has had immediate and complete relief of pain, and she walks normally and suffers no disability. All hyperæsthesia and hyperalgesia has disappeared. She was last observed on $8 / 6 / 42$.
It is very difficult to assess the effect of any $c$ operative procedure directed to the relief of $\mathbb{D}_{\mathbb{D}}$ causalgia, for all symptoms are subjective and spontaneous recovery is not uncommon. However, I believe that in this case the investigation was carried out with sufficient controls to warrant a belief that lumbar sympathectomy relieved the causalgia. I believe that in all such cases sympathetic: nerve block should be employed before operation.

\section{Conclusions}

Peripheral nerve block affords a very useful method of study of the function of peripheral nerves. Anatomical descriptions of the distribution of peripheral nerves should be based on data obtained by this technique as well as on data from cases of division. The method may be applied clinically in the differentiation of complete from partial and recovering lesions of peripheral nerves. The method is not harmful, and if the technique is satisfactory it is an extremely useful diagnostic procedure.

I am grateful to Dr. Feinstein of the Department of 음 Human Anatomy, Oxford, for preparing for me needles. insulated with phenyl resin.

\section{REFERFNCES}

Gasser, H. S., and Erlanger, G. (1929). Amer. J. Weddell, G., Guttmann, L., and Gutmann, E. (1941) Physiol., 88, 581.

Guttmann, L., and Highet, W. B. (1942). In the press.

Pollock, L. J. (1920). J. comp. Neurol., 32, 357.

J. Neurol. Psychiat., 4, 206.

Wood-Jones, F. (1921). Orthopadic Surgery of Injuries Vol. II. Edited by Sir Robert Jones. 